\title{
Targeting dual-specificity tyrosine phosphorylation- regulated kinase 2 (DYRK2) with a highly selective inhibitor for the treatment of prostate cancer
}

Kai Yuan

China Pharmaceutical University

Zhaoxing Li

China Pharmaceutical University

Wenbin Kuang

China Pharmaceutical University

Xiao Wang

China Pharmaceutical University

Minghui Ji

China Pharmaceutical University

Jiaxing Li

China Pharmaceutical University

Wenjian Min

China Pharmaceutical University

Weijiao Chen

China Pharmaceutical University

Chengliang Sun

China Pharmaceutical University

\section{Xiuquan Ye}

China Pharmaceutical University

Meiling Lu

China Pharmaceutical University

Liping Wang

University of Pittsburgh

Haixia Ge

Huzhou University

Yuzhang Jiang

Nanjing Medical University

Haiping Hao

China Pharmaceutical University

Yibei Xiao 
China Pharmaceutical University

Peng Yang ( $\square$ pengyang@cpu.edu.cn )

China Pharmaceutical University https://orcid.org/0000-0002-2613-941X

\section{Article}

Keywords: Hormonal Therapy, Co-crystal Structure, Safety Properties, Pharmacokinetic Profiles, Bioavailability

Posted Date: June 4th, 2021

DOl: https://doi.org/10.21203/rs.3.rs-541899/v1

License: (9) This work is licensed under a Creative Commons Attribution 4.0 International License. Read Full License

Version of Record: A version of this preprint was published at Nature Communications on May 25th, 2022. See the published version at https://doi.org/10.1038/s41467-022-30581-4. 


\section{Abstract}

Prostate cancer ( $\mathrm{PCa}$ ) is one of the most prevalent cancers in men worldwide, and hormonal therapy plays a key role in the treatment of PCa. However, the inevitable drug resistance of hormonal therapy makes it urgent and necessary to identify novel targets for PCa treatment. Herein, dual-specificity tyrosine phosphorylation-regulated kinase 2 (DYRK2) was found and confirmed to be highly expressed in the PCa tissues and cells, and knock-down of DYRK2 remarkably reduces PCa burden in vitro and in vivo. On the base of DYRK2 acting as a promising target, we further discovered a highly selective DYRK2 inhibitor YK2-69 and solved its co-crystal structure. Especially, YK-2-69 displayed great selectivity over 370 kinases and exhibited more potent anti-PCa efficacy than the first-line drug enzalutamide in vivo. Meanwhile, YK2-69 displayed excellent safety properties with maximal tolerable dose of more than $10,000 \mathrm{mg} / \mathrm{kg}$ and great pharmacokinetic profiles with $55.78 \%$ bioavailability. In summary, we identified DYRK2 as a novel drug target and verified its critical roles in PCa. Meanwhile, we discovered a highly selective DYRK2 inhibitor with favorable druggability for the treatment of PCa.

\section{Introduction}

Prostate cancer ( $\mathrm{PCa}$ ) is one of the most common cancers in men with an estimated incidence of 248,530 new cases in the U.S. alone, accounting for $26 \%$ of all new cancer cases in U.S. male in $2021^{1,2}$. The mortality rate of PCa ranks the second in U.S. male cancer and is expected to reach $11 \%$ of all male cancer deaths in $2021^{1,2}$. The majority of PCa primarily relies on androgens for survival and growth, and PCa treatment mainly focused on reducing hormone levels ${ }^{3-5}$. Currently, hormonal therapy, including the antiandrogens $s^{6,7}$, gonadotropin-releasing hormone (GnRH) agonists and antagonists ${ }^{8,9}$, androgen biosynthesis inhibitor ${ }^{10,11}$, and androgen receptor inhibitor ${ }^{12,13}$, has been developed. However, hormonal therapy can only delay PCa progression but is not a curative method for PCa treatment ${ }^{14,15}$. Ultimately, drug resistance of hormonal therapy is inevitable and most PCa patients developed to a metastatic, hormone-resistant state ${ }^{16,17}$. Therefore, despite the leading role of androgen in the PCa, it is necessary to identify novel regulators of PCa and target them for PCa treatment.

Dual-specificity tyrosine phosphorylation-regulated kinase 2 (DYRK2), which displays both tyrosine (Tyr) and serine/threonine (Ser/Thr) kinase activities, plays important while controversial roles in the human cancers ${ }^{18,19}$. Previously, DYRK2 was primarily considered as a cancer suppressor, which can promote phosphorylation of P53 to induce apoptosis ${ }^{20,21}$, facilitate degradation of c-JUN and c-MYC to inhibit the transition of cell cycle from $\mathrm{G} 1$ to $S$ phase 22,23 , and accelerate degradation of snail to suppress epithelialto-mesenchymal transition (EMT) and cell migration and so on ${ }^{24,25}$. Recently, the researches on the DYRK2 have gradually revealed its distinct role as an oncogene ${ }^{26-28}$. In multiple myeloma (MM) and triple-negative breast cancer (TNBC), DYRK2 phosphorylates Rpt3-Thr25 of the 26S proteasome to activate the $26 \mathrm{~S}$ proteasome, and then promotes the transition of cell cycle from $\mathrm{G} 1$ to $S$ phase $\mathrm{e}^{29,30}$. The inhibition of DYRK2 impedes 26S proteasome activity and suppresses the cell cycle progression to inhibit cell proliferation ${ }^{31,32}$. Therefore, DYRK2 is a potential target for the treatment of MM and TNBC. These 
researches revealed the critical and multifarious roles of DYRK2 in different cancers. However, the regulation mechanism of DYRK2 in PCa is still unclear and has not been reported. Especially, a few known small-molecule inhibitors of DYRK2 are lack of selectivity and druggability. Thus, it is urgent to reveal the function of DYRK2 in PCa and develop novel DYRK2 inhibitors with better potency and higher selectivity to treat PCa and other cancers.

In our work, DYRK2 was identified as a novel target for PCa treatment. High expression of DYRK2 was detected and confirmed in both PCa patients and cell lines. Knock-down of DYRK2 in PCa greatly promotes apoptosis, causes a G1 arrest of cell cycle and inhibits metastasis in vitro. Furthermore, knockdown of DYRK2 significantly inhibits tumor growth of PCa in a xenograft model. Through virtual screening and structural optimization, we developed a novel DYRK2 inhibitor YK-2-69 with high selectivity over 370 kinases, and its key interactions with DYRK2 were further confirmed by crystal structure. Excitedly, YK-2-69 displayed excellent safety properties, favorable pharmacokinetic profiles, and stronger suppression of PCa progression than the first-line PCa drug enzalutamide in vivo. Therefore, DYRK2 is an excellent biomarker in PCa diagnosis and a potent target to develop anti-PCa drugs. The newly discovered DYRK2 inhibitor YK-2-69 with high selectivity and favorable druggability provided a great preclinical candidate for the treatment of PCa.

\section{Results}

\section{Highly Expressed DYRK2 is a Potential Target in PCa}

To investigate the role of DYRK2 in PCa, we first mined the TCGA Cancer Genome Atlas to analyze the expression of DYRK2 in normal and PCa patients. We found the obviously higher expression of DYRK2 in PCa patients when compared with normal controls (Fig. 1a). Also, different to PCa patients with intermediate risk and below the age of 65 , the expression of DYRK2 was significantly higher in high risk and above the age of 65 PCa patients, respectively (Fig. 1b, C). Importantly, the relapse-free survival in patients with low expression of DYRK2 was remarkably better than those with high expression of DYRK2 (Fig. 1d). Immunohistochemistry of DYRK2 in patient-derived PCa tumors demonstrated that the expression of DYRK2 in malignancy PCa tissues was much higher than adjacent normal prostate tissues (Fig. 1e). Besides, the mRNA levels of DYRK2 were evaluated in 11 different cell lines. Among them, PC-3 and DU-145 PCa cell lines showed much higher DYRK2 mRNA levels compared with normal HEK-293 cell lines (Fig. 1f). The protein levels of DYRK2 in PC-3 and DU-145 cell lines were further determined by western blot (WB) analysis, and the results showed the higher expression of DYRK2 in PC-3 and DU-145 cell lines compared with prostate RWPE-1 cell lines (Fig. 1g). All these results indicated that DYRK2 is highly expressed in $\mathrm{PCa}$, which could be a potential target to develop anti-PCa drugs.

\section{Knock-down of DYRK2 Remarkably Reduces PCa Burden}

To further study the role of DYRK2 in PCa, we knocked down DYRK2 in DU-145 cells using shRNAs (Fig. 2a, b). DYRK2 depletion significantly suppressed the cell cloning (Fig. 2c), migration (Fig. 2d) and invasion in DU-145 cells (Fig. 2e). In addition, knock-down of DYRK2 caused a G1 arrest of the cell cycle 
and induced apoptosis (Supplementary Fig. 1a, b). The cell cycle-related proteins, including CDK4, CDK6, and pRB, which promoted the cell cycle progression, were down-regulated in DYRK2-depleted DU-145 cell lines. In contrast, cyclin-dependent kinase inhibitors (CKIs) P21 and P27, which inhibited the cell cycle, were up-regulated (Fig. 2f). The cell apoptosis-related proteins, such as P53 and Cleaved PARP, were upregulated as well. The increased expression of E-cadherin was also detected in the DYRK2-depleted DU145 cell lines, which demonstrated invasion and metastasis was suppressed (Fig. 2f). Furthermore, to determine the effects of DYRK2 knock-down on PCa growth in vivo, we subcutaneously implanted the shVehicle and shDYRK2 DU-145 cells into the nude mice. The tumor growth was significantly inhibited (Fig. 2 g) while the body weight of mice increased normally when compared with the shVehicle group (Supplementary Fig. 1c). H\&E staining and Ki-67 immunohistochemical analysis of tumor tissues indicated that knock-down of DYRK2 exhibited potent efficacy of killing tumor cells (Supplementary Fig. 1d) and inhibiting PCa cell proliferation (Supplementary Fig. 1e). The WB analysis of the tumor tissue demonstrated that CDK4, CDK6, pRB, and cyclin D1 were down-regulated, while P27 was up-regulated in vivo (Fig. 2h). In summary, the down-regulation of DYRK2 remarkably reduces PCa tumor burden in vitro and in vivo, suggesting that DYRK2 plays critical function in regulating $\mathrm{PCa}$ and is a potential therapeutic target for the treatment of PCa.

\section{YK-2-69 was Discovered as a Highly Selective DYRK2 Inhibitor}

Considering the highly expression level and critical regulation roles of DYRK2 in PCa, we took DYRK2 as a potential drug target and conducted a structure-based virtual screening of the Specs database and an inhouse library to identify DYRK2 inhibitors (Fig. 3a and Supplementary Fig. 2, see Methods for details) ${ }^{33}$. Compound 12 was identified as a top hit, which displayed potent inhibition on DYRK2 with an $\mathrm{IC}_{50}$ value of $263 \mathrm{nM}$. The intense connection between compound 12 and DYRK2 was disclosed by the binding mode, which indicated that fluorine formed one hydrogen bone with Lys-251 and two halogen bonds with Glu-266 and Asp-368, respectively. In addition, the pyrimidine ring of compound $\mathbf{1 2}$ formed $\pi-\pi$ stacking interactions with Phe-301 (Supplementary Fig. 3a, b). Through systematic structure optimization, a novel compound YK-2-69 was obtained as a better inhibitor of DYRK2 with an $\mathrm{IC}_{50}$ value of $9 \mathrm{nM}$ (Fig. 3B). In particular, YK-2-69 showed great selectivity to DYRK subfamily with 60-fold selectivity over DYRK1B and more than 100-fold selectivity over DYRK1A, DYRK3 and DYRK4 (Supplementary Fig. 3c). To further estimate kinase selectivity of YK-2-69, its inhibitory activities against 370 kinases were tested at $1 \mu \mathrm{M}$ concentration. Besides CDK4/6 ${ }^{34}$, YK-2-69 exhibited great selectivity over 370 kinases (Fig. 3c and Supplementary Fig. 3d). Taken together, we discovered YK-2-69 as a novel DYRK2 ligand with great inhibitory activity and high selectivity.

To explore exact interaction of YK-2-69 with DYRK2 and elucidate the mechanism, we determined the cocrystal structure of YK-2-69 with DYRK2 at a high resolution of 2.5 (PDB ID: 7EJV, Table S1). The cocrystal structure showed that YK-2-69 binds to the ATP-binding pocket of DYRK2 (Fig. 3d). The benzothiazole and pyrimidine rings are located deep into the ATP binding site. This orientation placed the pyrimidine ring adjacent to the Lys- 231 . The pyrimidine ring and the linked secondary amine interacted 
with Lys-231 in the form of two hydrogen bonds. The tailed piperazine ring extended out and the conjoint carbonyl formed a hydrogen bond with the amino side chain of Asn-234 (Fig. 3e).

DYRK2 exerts its kinase function by phosphorylating serine/threonine residues and was reported to phosphorylate c-MYC at Ser62 22 . Our results revealed that p-c-MYC could interact with DYRK2 by the immunoprecipitation assay (Fig. 3f). Meanwhile, we found that YK-2-69 can down-regulate the phosphorylation level of c-MYC(Ser62) in a dose dependent manner (Fig. 3g). These results demonstrated that YK-2-69 selectively binds to DYRK2 and greatly inhibits its kinase activity.

\section{YK-2-69 Inhibited PCa Cell Growth and Migration in Vitro}

Once we confirmed YK-2-69 as a potent and selective DYRK2 inhibitor, we further investigated its effects on PCa cells. YK-2-69 showed potent inhibitory activity against the proliferation of PC-3 and DU-145 cell lines with $\mathrm{IC}_{50}$ values of 1.069 and $3.302 \mu \mathrm{M}$, respectively (Fig. 4a). But for shDYRK2 DU-145 cells, YK-269 exhibited almost no inhibitory activity on the proliferation even at $80 \mu \mathrm{M}$ (Fig. 4b), which further confirmed the selective on-target activity of YK-2-69 to DYRK2. Meanwhile, YK-2-69 significantly inhibited the cell growth (Fig. 4c) and cloning formation (Fig. 4d) of DU-145 cells in a dose dependent manner, which is similar to knocking down DYRK2 in the DU-145 cell lines. Same as DYRK2 knockdown reduced epithelial-mesenchymal transition (EMT, Fig. 2d, e), YK-2-69 also remarkably inhibited the migration (Fig. 4 e) and invasion (Fig. 4f) of DU-145 cell lines in a dose dependent manner. All these results confirmed that YK-2-69 greatly reduced cell growth and EMT through inhibiting DYRK2.

To investigate the possible role of YK-2-69 on cell cycle and apoptosis, we conducted flow cytometry analysis. The treatment of DU-145 cells with YK-2-69 increased cell cycle arrest at the G0/G1 phase (Supplementary Fig. 4a) and caused a significant increase of the apoptotic cell population in a concentration dependent manner (Supplementary Fig. 4b). Compared to the negative control, the lysates of the DU-145 cells treated with YK-2-69 decreased cell cycle-related protein levels of p-RB, CDK4 and CDK6 as well increased P21 and P27, and also increased apoptosis-related protein levels of P53 and PARP as well decreased XIAP (Fig. 4h). In summary, knock-down of DYRK2 and small-molecule inhibitor YK-2-69 displayed same effects on DU-145 cells in vitro, which inhibited cell growth through G1 arrest and apoptosis induction, and decreased the EMT activity.

\section{DYRK2 KD Target Similar Signaling Pathways to YK-2-69 Treatment in PCa Cells}

To investigate which genes and signaling pathways are responsible for the anti-prostate cancer function of DYRK2 inhibitors, we performed transcriptome-wide RNA-sequencing analysis of DYRK2 KD- and YK-269- treated DU-145 human PCa cells as well as control cells. After knock-down of DYRK2, 1263 differentially expressed genes were detected, of which nearly $50 \%$ (546) were also significantly differentially expressed after YK-2-69 treatment (Supplementary Fig. 5a). It is worth noting that the vast majority of the increased pathways of DYRK2 KD (90 out of 93, 96.8\%) can be enriched by YK-2-69 treatment (Fig. 5a). Similarly, DYRK2 KD also inhibited most of the signaling pathways that are inhibited by YK-2-69 (Fig. 5a). These results strongly suggest that DYRK2 inhibitor YK-2-69 shares the same role as 
DYRK2 KD in key signaling pathways that control cell cycle, cell proliferation, and cell survival in DU-145 cells. In addition, we treated shDYRK2 and YK-2-69 as a separate group and reanalyzed the sequencing data between this group and the control group (including the shVehicle group and the WT group). Consistently, DYRK2 KD and YK-2-69 inhibited MYC targets, G2M checkpoints, and E2F targets (Fig. 5b). By independent analysis of two different comparisons, we found that both DYRK2 KD and YK-2-69 treatments induced significant inhibition of MYC targets, which may contribute to the inhibitory effects of YK-2-69 and DYRK2 KD on cell cycle and proliferation (Fig. 5c). Global genome-enrichment analysis showed that DYRK2 KD and YK-2-69 treatment exhibited similar effects on the regulation of a set of functionally important signaling pathways. Both the knock-down of DYRK2 and YK-2-69 treatment significantly down-regulated the genes rich in MYC target V1, MYC target V2 and Mitotic SPINDLE (Supplementary Fig. 5b). Meanwhile, the up-regulated genes were rich in IL6-JAK-STAT3 SIGNAING and KRAS SIGNAING DN (Fig. 5d). Such data suggests that DYRK2 KD and YK-2-69 play important and similar roles in cell proliferation inhibition and apoptosis induction.

Through the heat map (Supplementary Fig. 5c), we found significant expression changes in human regulator ribosome synthesis 1 (RRS1) and cyclin G2 (CCNG2). RRS1, an essential nuclear protein involved in ribosome biogenesis, is overexpressed in some human cancers ${ }^{35}$, and downregulation of RRS1 causes a G1 arrest of cell cycle ${ }^{36}$. Meanwhile, previous studies have shown that overexpression of CCNG2 can induce apoptosis and inhibit cell proliferation ${ }^{37,38}$. The results of transcriptome-wide RNAsequencing indicated that YK-2-69 and DYRK2 KD significantly down-regulated RRS1 (Fig. 5e) and upregulated CCNG2 (Fig. 5f). The experimental results of WB and QRT-PCR further confirmed that RRS1 expression was downregulated (Fig. $5 \mathrm{~g}$ and Supplementary Fig. 5d) and CCNG2 expression was upregulated (Fig. 5h and Supplementary Fig. 5e) regardless of knocking down DYRK2 or YK-2-69 treatment. These results suggested that RRS1 and CCNG2 pathways may play important roles in DYRK2 regulation mechanism and YK-2-69 treatment to PCa cells.

\section{YK-2-69 Displayed Excellent Safety Properties and Great Pharmacokinetic Profiles}

To evaluate the toxic effects of DYRK2 inhibitor YK-2-69 in vivo, the ICR mice ( $n=10$, each group) were orally administrated YK-2-69 in the single dose of 2,500 mg/kg, 5,000 mg/kg and 10,000 mg/kg, respectively. No abnormality and death were observed in mice of each group in 14 days. Also, no difference was detected in the mice body weight (Supplementary Fig. 6a) and main organs, including heart, liver, spleen, lung and kidney, between drug-treated and control groups (Supplementary Fig. 6b, c). These data confirmed the excellent safety properties of YK-2-69 in vivo.

To further explore the pharmacokinetic profiles of YK-2-69, the Sprague-Dawley (SD) rats ( $n=3$, each group) were administrated YK-2-69 by oral and intravenous injection (Table 1). In intravenous group, the half-life $\left(\mathrm{t}_{1 / 2}\right), \mathrm{T}_{\text {max }}, \mathrm{C}_{\text {max }}$, and $\mathrm{AUC}_{0-\infty}$ values were $2.99 \mathrm{~h}, 0.033 \mathrm{~h}, 974 \mathrm{ng} / \mathrm{mL}$, and 1,503 $\mathrm{h} * \mathrm{ng} / \mathrm{mL}$, respectively. In oral administration group, YK-2-69 displayed the pharmacokinetic parameters as follows: $\mathrm{t}_{1 / 2}=5.08 \mathrm{~h}, \mathrm{~T}_{\max }=4 \mathrm{~h}, \mathrm{C}_{\max }=674.3 \mathrm{ng} / \mathrm{mL}$, and $\mathrm{AUC}_{0-\infty}=8,384 \mathrm{~h} * \mathrm{ng} / \mathrm{mL}$. Moreover, the oral 
bioavailability of YK-2-69 is 55.78\%. In summary, these results demonstrated the favorable druggability of YK-2-69 with excellent safety properties and great pharmacokinetic profiles in vivo.

Table 1 Pharmacokinetic parameters of compound YK-2-69 in SD rats ${ }^{a}$

\begin{tabular}{|c|c|c|c|c|c|c|c|c|}
\hline Compd. & Admin. & $\begin{array}{l}\mathrm{C}_{\max } \\
(\mathrm{ng} / \mathrm{mL})\end{array}$ & $\begin{array}{l}\mathrm{AUC}_{0-\infty} \\
\left(\mathrm{h}_{\star} \mathrm{ng} / \mathrm{mL}\right)\end{array}$ & $\begin{array}{l}\mathrm{MRT}_{0-\infty} \\
\text { (h) }\end{array}$ & $\begin{array}{l}T_{\max } \\
\text { (h) }\end{array}$ & $\begin{array}{l}t_{1 / 2} \\
\text { (h) }\end{array}$ & $\begin{array}{l}\mathrm{CL} \\
(\mathrm{mL} / \mathrm{h} / \mathrm{kg})\end{array}$ & $\mathrm{F}(\%)$ \\
\hline \multirow[t]{2}{*}{ YK-2-69 } & IV & 974 & 1,503 & 3.49 & 0.033 & 2.99 & 668.8 & - \\
\hline & PO & 674.3 & 8,384 & 8.94 & 4.00 & 5.08 & 511 & 55.78 \\
\hline
\end{tabular}

${ }^{a}$ Values are the average of three runs. $\mathrm{C}_{\text {max }}$, maximum concentration; $\mathrm{AUC}$, area under the plasma concentration-time curve; MRT, mean residence time; $t_{1 / 2}$, half-life; $\mathrm{CL}$, clearance; $F$, oral bioavailability. Dose: p.o. at $10 \mathrm{mg} / \mathrm{kg}$. Dose: i.v. at $1 \mathrm{mg} / \mathrm{kg}$

\section{YK-2-69 Displayed More Potent Suppression on PCa than First-line Drugs Enzalutamide and Palbociclib in Vivo.}

To evaluate antitumor activities of YK-2-69 in vivo, the DU-145 xenograft mouse model was established. Enzalutamide, the first-line PCa drug, and palbociclib, the selective CDK4/6 inhibitor in the market, were selected as the positive controls since CDK4/ 6 are down-regulated in DU-145 cells when treated by YK-269. They were administered orally once a day for seven consecutive weeks. The low dose of YK-2-69 (100 $\mathrm{mg} / \mathrm{kg}$ ) displayed similar antitumor activities with enzalutamide but better activities than palbociclib (Fig. $6 a)$. While the high dose of YK-2-69 $(200 \mathrm{mg} / \mathrm{kg})$ demonstrated much better antitumor activities than both enzalutamide and palbociclib. Especially, different from enzalutamide and palbociclib which only delayed the tumor growth, the high dose of YK-2-69 not only suppressed the growth of tumor, but also decreased the volume of tumor since the $31^{\text {st }}$ day (Fig. 6a). It is noteworthy that the body weight of mice also increased gradually in the high dose group (Fig. 6b). H\&E staining of tumor tissues and immunohistochemical analysis of Ki-67 expression indicated that YK-2-69 exhibited potent efficacy in killing PCa cells and inhibiting cell proliferation (Fig. 6c, d and e). Similar to the in vitro data, the WB analysis of the tumor tissue excised from DU-145 xenograft mouse also indicated that YK-2-69 decreased cell cycle-related protein levels of CDK4/6, cyclin D1, pRB, RRS1 as well increased P27, and increased apoptosis-related protein levels of cleaved PARP (Fig. 6f). Taken together, YK-2-69 displayed much better anti-tumor activity than first-line drugs enzalutamide and palbociclib in vivo.

On the basis of these results, YK-2-69 selectively binds to DYRK2 and inhibits its kinase activity, via which down-regulates RRS1 and further up-regulates P21 and P27 to suppress CDK4/6 (Fig. 6g). The inhibition of DYRK2 by YK-2-69 can also suppress the phosphorylation of c-MYC. RRS1-P21/27-CDK4/6 and DYRK2-c-Myc axes can restrain the transition from $\mathrm{G} 1$ to $S$ phase of cell cycle and eventually inhibits cell proliferation. Simultaneously, down-regulation of DYRK2 by YK-2-69 can increase P53 and CCNG2 level, which promotes apoptosis. In summary, this highlights DYRK2 inhibition by YK-2-69 as a promising 
combination to promote apoptosis and inhibit proliferation, which provides a "kill two birds with one stone" regimen of $\mathrm{PCa}$.

\section{Discussion}

The expression level of DYRK2 widely depends on the human tumor tissues, and it plays diverse roles in the occurrence and development of various cancers, which highlights the possibility of DYRK2 as a potential target for cancer treatment. Previous reports mainly considered DYRK2 as a cancer suppressor, which induces apoptosis through promoting phosphorylation of P53 in colorectal cancer ${ }^{39}$, inhibits cell cycle from $\mathrm{G} 1$ to $S$ phase via degrading c-JUN and c-MYC in breast cancer ${ }^{22}$, and suppress EMT by accelerating SNAIL degradation in glioma ${ }^{40}$. But not all reports demonstrate that DYRK2 inhibits cancer initiation and growth as a cancer suppressor. Recent reports revealed the DYRK2 accelerates $\mathrm{G} 1$ to $\mathrm{S}$ phase transition of cell cycle through regulating $26 \mathrm{~S}$ proteasome activity, and is considered as an oncogene in MM and TNBC 26,31 . Considering the critical function of DYRK2 in cancers, we conducted data-mining of the TCGA Cancer Genome Atlas to analyze its expression levels in a panel of cancers, and found the high expression of DYRK2 in PCa, which was positively correlated with clinical prognosis and mortality (Fig. 1A-1D). However, the function of DYRK2 in PCa is still unclear. In our work, DYRK2 was found to be highly expressed in PCa patient samples and cell lines (Fig. 1E-1G). The knock-down of DYRK2 in DU-145 cells significantly inhibited cell cloning, migration, and invasion, caused a G1 arrest of cell cycle, and induced apoptosis (Fig. 2A-2F). In addition, knock-down of DYRK2 significantly inhibited tumor growth in vivo (Fig. $2 \mathrm{G}$ and $2 \mathrm{H}$ ). All these results indicate that DYRK2 is a potential therapeutic target for the treatment of PCa.

Although several DYRK2 inhibitors were discovered and exhibited anti-cancer activity in MM and TNBC ${ }^{31-}$ 32 , their selectivity over DYRK family members and drug-like properties need to be further modified. To develop more potent and selective DYRK2 inhibitors, we performed a high-throughput virtual screening and identified a DYRK2 hit with novel chemical scaffold, which was further modified to offer the highly selective inhibitor YK-2-69. YK-2-69 exhibited strong inhibition to DYRK2 with an $\mathrm{IC}_{50}$ value of $9 \mathrm{nM}$ and showed great selectivity over DYRK subfamily and a panel of 370 kinases (Fig. 3A-3C). To explore the clear mechanism and elucidate the exact interaction of YK-2-69 with DYRK2, we solved their cocrystal structure with a high resolution at $2.5 \AA$ (PDB ID: 7EJV), which showed the essential interaction residues Lys-231 and Asn-234 (Fig. 3D and 3E).

Similar to knock-down of DYRK2 in the DU-145 cells, YK-2-69 also significantly inhibited cell growth through G1 arrest and apoptosis induction, and decreased the EMT activity (Fig. 4). Transcriptome-wide RNA sequencing assays demonstrated that YK-2-69 regulates a set of functionally important biological pathways in cell proliferation inhibition and apoptosis induction, which is similar as knock-down of DYRK2 (Fig. 5). Importantly, YK-2-69 displayed excellent safety properties with maximal tolerable dose of more than 10,000 mg/kg (Fig. S6) and great pharmacokinetic profiles with $55 \%$ bioavailability (Table 1) in vivo. Moreover, YK-2-69 exhibited much better antitumor activities than both enzalutamide and 
palbociclib (Fig. 6). Especially, YK-2-69 not only suppressed the growth of tumor, but also decreased the volume of tumor, which is completely different from enzalutamide and palbociclib. These results provided us a possibility that YK-2-69 may contribute to solve the drug-resistant dilemma of enzalutamide as hormonal therapy. YK-2-69 exhibited much higher anti-PCa efficacy via synergistic regulation on a panel of pathways, including DYRK2-RRS1-P21/27-CDK4/6, DYRK2-c-Myc and so on, to promote apoptosis and inhibit proliferation. This might be one of the possible reasons why YK-2-69 exhibited significant anti-PCa efficacy.

The latest data from International Agency for Research on Cancer reports (World Cancer Report 2020) that prostate cancer is the second most common cancer in men worldwide, with an estimated 1.3 million new cases and 360,000 deaths in 2020 . However hormonal therapy, the leading treatment of PCa, is only a remission but not a cure for $\mathrm{PCa}$, and most $\mathrm{PCa}$ patients became resistant to hormonal therapy at last. Therefore, it is urgent and meaningful to identify novel targets and develop new drugs for PCa. Our work identified DYRK2 as a novel drug target and verified its critical roles in PCa, which offers a new direction for the treatment of PCa. Especially, we discovered a highly selective DYRK2 inhibitor with favorable druggability, which can be used as a small-molecule probe for biological studies and also provide a great candidate for PCa clinical treatment. Since DYRK2 plays critical roles in various human cancers, targeting DYRK2 could also provide new opportunity for other patients with refractory cancers.

\section{References}

1. Siegel, R.L., Miller, K.D., Fuchs, H.E. \& Jemal, A. Cancer Statistics, 2021. Ca-Cancer J. Clin. 71, 7-33 (2021).

2. Siegel, R.L., Miller, K.D. \& Jemal, A. Cancer statistics, 2020. Ca-Cancer J. Clin. 70, 7-30 (2020).

3. Reis, L.O. Old issues and new perspectives on prostate cancer hormonal therapy: the molecular substratum. Med. Oncol. 29, 1948-1955 (2012).

4. Vis, A.N. \& Schroder, F.H. Key targets of hormonal treatment of prostate cancer. Part 1: the androgen receptor and steroidogenic pathways. BJU Int. 104, 438-448 (2009).

5. Estebanez-Perpina, E., Bevan, C.L. \& McEwan, I.J. Eighty Years of Targeting Androgen Receptor Activity in Prostate Cancer: The Fight Goes on. Cancers 13, 509 (2021).

6. Wirth, M.P., Hakenberg, O.W. \& Froehner, M. Antiandrogens in the treatment of prostate cancer. Eur. Urol. 51, 306-314 (2007).

7. Maitland, N.J. Resistance to antiandrogens in prostate cancer: Is it inevitable, intrinsic or induced? Cancers 13, 327 (2021).

8. Lambalk, C.B., et al. GnRH antagonist versus long agonist protocols in IVF: a systematic review and meta-analysis accounting for patient type. Hum. Reprod Update 23, 560-579 (2017).

9. Tarlatzis, B.C. \& Kolibianakis, E.M. GnRH agonists vs antagonists. Best Pract. Res. Clin. Obstet. Gynaecol. 21, 57-65 (2007). 
10. Rehman, Y. \& Rosenberg, J.E. Abiraterone acetate: oral androgen biosynthesis inhibitor for treatment of castration-resistant prostate cancer. Drug Des. Dev. Ther. 6, 13-18 (2012).

11. Bryce, A. \& Ryan, C.J. Development and clinical utility of abiraterone acetate as an androgen synthesis inhibitor. Clin. Pharmacol. Ther. 91, 101-108 (2012).

12. Scott, L.J. Enzalutamide: a review in castration-resistant prostate cancer. Drugs $78,1913-1924$ (2018).

13. Hussain, M., et al. Enzalutamide in men with nonmetastatic, castration-resistant prostate cancer. New Engl. J. Med. 378, 2465-2474 (2018).

14. Stavridi, F., Karapanagiotou, E.M. \& Syrigos, K.N. Targeted therapeutic approaches for hormonerefractory prostate cancer. Cancer Treat. Rev. 36, 122-130 (2010).

15. Seruga, B. \& Tannock, I.F. The changing face of hormonal therapy for prostate cancer. Ann. Oncol. 19, 79-85 (2008).

16. Sartor, O. \& de Bono, J.S. Metastatic prostate cancer. New Engl. J. Med. 378, 645-657 (2018).

17. Yap, T.A., Zivi, A., Omlin, A. \& de Bono, J.S. The changing therapeutic landscape of castrationresistant prostate cancer. Nat. Rev. Clin. Oncol. 8, 597-610 (2011).

18. Tandon, V., de la Vega, L. \& Banerjee, S. Emerging roles of DYRK2 in cancer. J. Biol. Chem. 296, 100233 (2021).

19. Correa-Saez, A., et al. Updating dual-specificity tyrosine-phosphorylation-regulated kinase 2 (DYRK2): molecular basis, functions and role in diseases. Cell Mol. Life Sci. 77, 4747-4763 (2020).

20. Taira, N., Nihira, K., Yamaguchi, T., Miki, Y. \& Yoshida, K. DYRK2 is targeted to the nucleus and controls p53 via Ser46 phosphorylation in the apoptotic response to DNA damage. Mol. Cell 25, 725738 (2007).

21. Yoshida, K. Role for DYRK family kinases on regulation of apoptosis. Biochem. Pharmacol. 76, 13891394 (2008).

22. Taira, N., et al. DYRK2 priming phosphorylation of c-Jun and c-Myc modulates cell cycle progression in human cancer cells. J. Clin. Invest. 122, 859-872 (2012).

23. Becker, W. Emerging role of DYRK family protein kinases as regulators of protein stability in cell cycle control. Cell Cycle 11, 3389-3394 (2012).

24. Yamaguchi, N., et al. DYRK2 regulates epithelial-mesenchymal-transition and chemosensitivity through Snail degradation in ovarian serous adenocarcinoma. Tumor Biol. 36, 5913-5923 (2015).

25. Mimoto, R., et al. DYRK2 controls the epithelial-mesenchymal transition in breast cancer by degrading Snail. Cancer Letters 339, 214-225 (2013).

26. Guo, X., et al. Site-specific proteasome phosphorylation controls cell proliferation and tumorigenesis. Nat. Cell Biol. 18, 202-212 (2016).

27. Huibregtse, J.M. \& Matouschek, A. Ramping up degradation for proliferation. Nat. Cell Biol. 18, 141142 (2016). 
28. Moreno, R., et al. The stress-responsive kinase DYRK2 activates heat shock factor 1 promoting resistance to proteotoxic stress. Cell Death. Differ. doi: 10.1038/s41418-020-00686-8 (2020).

29. VerPlank, J.J.S. \& Goldberg, A.L. Regulating protein breakdown through proteasome phosphorylation. Biochem. J. 474, 3355-3371 (2017).

30. Guo, X. \& Dixon, J.E. The $26 S$ proteasome: A cell cycle regulator regulated by cell cycle. Cell Cycle 15, 875-876 (2016).

31. Banerjee, S., et al. Ancient drug curcumin impedes $26 \mathrm{~S}$ proteasome activity by direct inhibition of dual-specificity tyrosine-regulated kinase 2. Proc. Natl. Acad. Sci. USA 115, 8155-8160 (2018).

32. Banerjee, S., et al. Inhibition of dual-specificity tyrosine phosphorylation-regulated kinase 2 perturbs 26 S proteasome-addicted neoplastic progression. Natl. Acad. Sci. USA 116, 24881-24891 (2019).

33. Yuan, K., et al. Discovery of novel and selective CDK4/6 inhibitors by pharmacophore and structurebased virtual screening. Future Med. Chem. 12, 1121-1136 (2020).

34. Yuan, K., et al. Selective inhibition of CDK4/6: A safe and effective strategy for developing anticancer drugs. Acta. Pharmacol. Sin. B 11, 30-54 (2021).

35. Yan, X., Wu, S., Liu, Q. \& Zhang, J. RRS1 promotes retinoblastoma cell proliferation and invasion via activating the AKT/mTOR signaling pathway. BioMed. Res. Int. 2020, 2420437 (2020).

36. Song, J.L., et al. Functional role of RRS1 in breast cancer cell proliferation. J. Cell. Mol. Med. 22, 6304-6313 (2018).

37. Zhang, D.F., et al. CCNG2 overexpression mediated by AKT inhibits tumor cell proliferation in human astrocytoma cells. Front Neurol. 9, 255 (2018).

38. Don, A.S.A., et al. Cyclin $\mathrm{G} 2$ is a centrosome-associated nucleocytoplasmic shuttling protein that influences microtubule stability and induces a p53-dependent cell cycle arrest. Exp. Cell Res. 312, 4181-4204 (2006).

39. Kumamoto, T., et al. Impairment of DYRK2 by DNMT1-mediated transcription augments carcinogenesis in human colorectal cancer. Int. J. Oncol. 56, 1529-1539 (2020).

40. Shen, Y.F., et al. Regulation of glioma cells migration by DYRK2. Neurochem. Res. 42, 3093-3102 (2017).

\section{Methods}

Protein expression and purification. DYRK2 ${ }^{72-479}$ with an $\mathrm{N}$-terminal $6 \times$ His affinity tag and TEV protease cleavage site was cloned into pET28a vector. Sequence verified plasmid was transformed into $E$. coli BL21 (DE3) cell. Bacterial cultures were grown at $37^{\circ} \mathrm{C}$ in $\mathrm{LB}$ medium to an $\mathrm{OD}_{600}$ of 0.8 before induced with $0.5 \mathrm{mM}$ isopropyl $\beta$-D-1-thiogalactopyranoside (IPTG) overnight at $25^{\circ} \mathrm{C}$. Cells were collected by centrifugation and suspended in the lysis buffer containing $20 \mathrm{mM} \mathrm{HEPES}, \mathrm{pH} 7.5,500 \mathrm{mM} \mathrm{NaCl}, 20 \mathrm{mM}$ imidazole and $10 \%$ glycerol, and disrupted by sonication. The lysate was centrifuged at 15,000 r.p.m for 30 min twice at $4{ }^{\circ} \mathrm{C}$. After centrifugation, the supernatant was initially purified using Ni-NTA column (GE Healthcare), and then eluted with lysis buffers supplemented with $300 \mathrm{mM}$ imidazole. Eluent recombinant 
protein with the $\mathrm{His}_{6}$-tag was subsequently cleaved using TEV protease at $4{ }^{\circ} \mathrm{C}$ overnight. The cleaved protein was further purified using reverse affinity chromatography and size-exclusion chromatography in buffer containing $20 \mathrm{mM}$ HEPES, pH 7.5, $250 \mathrm{mM} \mathrm{NaCl}$. The pure protein was concentrated to 11.2 $\mathrm{mg} / \mathrm{mL}$ and flash-frozen with liquid nitrogen for later usage.

Co-crystallization, data collection and structure determination. DYRK2 $2^{72-479}(10 \mathrm{mg} / \mathrm{mL})$ was incubated with $1 \mathrm{mM}$ YK-2-69 at $4{ }^{\circ} \mathrm{C}$ before crystallization. The protein-YK-2-69 mixture was then mixed in a 1:1 ratio with crystallization solution ( $0.1 \mathrm{M}$ sodium citrate $\mathrm{pH} 5.5,8 \% \mathrm{PEG} 3350)$ in a final drop size of $2 \mu \mathrm{L}$. The initial DYRK2-YK-2-69 crystals were grown at $4{ }^{\circ} \mathrm{C}$ by the hanging-drop vapor diffusion method and optimized by seeding. Cuboid-shaped crystals appeared after 2-7 days. Crystals were cryoprotected in the crystallization solution supplemented with $30 \%$ glycerol before frozen in liquid nitrogen. The X-ray diffraction data were collected at Shanghai Synchrotron Radiation Facility (SSRF) beamline BL19U. The diffraction data were indexed, integrated, and scaled using HKL-2000 (HKL Research). The structure was determined by molecular replacement using the published DYRK2 structure (PDB ID: 5LXD). A clear electron density was observed in the center of the ATP binding pocket after molecular replacement. YK-269 was fitted using the LigandFit program in Phenix. The structural model was further adjusted in Coot and refined using Phenix. The quality of the structural model was checked using the MolProbity program in Phenix. The crystallographic data and refinement statistics are summarized in Table S1.

Immunohistochemistry of prostate cancer patient samples. The prostate patient samples were obtained from Huai'an First People's Hospital, Nanjing Medical University. Prostate cancer (PCa) tissues and adjacent normal prostate tissues were fixed in $4 \%$ formaldehyde solution and processed routinely for paraffin embedding. Sections were cut at around $4 \mu \mathrm{m}$ thickness and placed on glass slides, and stained with DYRK2 antibody and Sheep anti-rabbit/mouse polymer. Add 2 drops of freshly prepared DAB solution to each sheet, and then Re-dyeing and dehydration seal. Sections were scanned by digital pathology scanner.

Cell culture. The PCa DU-145 cells were obtained from American Type Culture Collection (ATCC) and cultured in endotoxin-free RPMI1640 supplemented with 10\% fetal bovine serum (FBS) (Gibco); RWPE-1 normal epithelial prostatic cells (ATCC) were cultured in KM supplemented with 10\% FBS; PC-3 human PCa cells (ATCC), A549 human lung cancer cells (ATCC) were cultured in F-12K with 10\%FBS, Panc-1 and HEK-293 cells (ATCC) were cultured in DMEM with 10\%FBS; K562, HL-60, NCl-H460 and RPMI8226 were obtained from National Collection of Authenticated Cell Cultures and kept in RPMI1640 with 10\% FBS; Breast tumor cell line, MDA-MB-231, was purchased from ATCC and cultivated in L-15 with $10 \%$ FBS. The pancreatic cancer cell line BXPC-3 was maintained in RPMl1640 with 10\% FBS. All the cells are not among commonly misidentified cell lines, and were tested for mycoplasma contamination annually using a PCR Mycoplasma Detection Kit (G238, Applied Biological Materials Inc.). In order to prevent potential contamination, all the media were supplemented with Penicillin-Streptomycin (C0222, Beyotime) and Plasmocin prophylactic (ant-mpp, InvivoGen) according to the manufacturer's instructions. 
Cell proliferation assays. We seeded 5,000 cells/well DU-145, PC-3 cells on 96-well plate and treated with DMSO or DYRK2 inhibitor YK-2-69 for $72 \mathrm{~h}$. Add $10 \mathrm{uL}$ of CCK8 reagent to each well, mix lightly, and incubate the plates in an incubator at $37^{\circ} \mathrm{C}$ with $5 \% \mathrm{CO}_{2}$ for $1-4 \mathrm{~h}$. The incubated cell culture plate was placed on the enzyme plate analyzer and the absorbance value was measured at $450 \mathrm{~nm}$. 2,000 cells/well PCa cells (DU-145) were seeded and subjected to DYRK2 inhibitor YK-2-69 treatment for 5 days and the cell culture plate was placed on the enzyme plate analyzer every day and the absorbance value was measured at $450 \mathrm{~nm}$.

Lentivirus production and infection. Lentivirus-induced DYRK2 KD was modified in DU-145 cells. In brief, $0.5 \mu \mathrm{g}$ pMD2.G, $0.3 \mu \mathrm{g}$ pMDLg/pRRE and $0.7 \mu \mathrm{g}$ PrSV-Rev and $1.5 \mu \mathrm{g}$ PLkO-shDYRK2 or PLkO-shNC were co-transfected into 293T cells in cell culture dish. The effectene transfection reagent packs lentiviruses. Lentivirus particles were collected at $48 \mathrm{~h}$ and $72 \mathrm{~h}$ after transfection and transferred directly into DU-145 cells containing $4 \mu \mathrm{g} / \mathrm{mL}$ polypropylene. PCa cells, including lentiviruses, were then rotated and inoculated for $90 \mathrm{~min}$ at $32^{\circ} \mathrm{C}$ and $1200 \mathrm{rpm}$. Finally, $1 \mu \mathrm{g} / \mathrm{mL}$ puromycin was added to cultured PCa cells $48 \mathrm{~h}$ after rotation inoculation to select positive infected cells. The shRNA targeting oligo sequence:

\section{CCGGGCAGGGTAGAAGCGGTATTAACTCGAGTTAATACCGCTTCTACCCTGCTTTTTG}

Real-time quantitative PCR (RT-qPCR). DYRK2 KD cells or DU-145 cells were treated with vehicle control or YK-2-69 at indicated concentrations for $72 \mathrm{~h}$. All the cells with total RNA isolated with the TRIZOL reagent was subjected to reverse transcription using the PrimeScriptTM RT reagent Kit (RR047Q, Takara). RTqPCR reactions were performed with the THUNDERBIRDSYBR qPCR Mix (QPS201, TOYOBO) and primers listed in Table S2. Gene expression was calculated using the comparative DDCT method with the GAPDH for normalization.

Immunoprecipitation. We lyse the cells in PBS (20\% Triton X-100, 10\% CHAPS, and Protease Inhibitor Mixture (Roche) for 30 minutes at room temperature. After centrifugation for 5 minutes, the supernatant was incubated with $10 \mu \mathrm{L}$ of anti-DYRK2 antibody (Santa Cruz Biotechnology Inc) for 2 hours at $4{ }^{\circ} \mathrm{C}$. Rabbit IgG was used as a control. Incubate with antibody and supernatant with $2 \%$ BSA and $10 \mathrm{mg}$ protein A-Sepharose beads (P1406, Sigma-Aldrich) at $4{ }^{\circ} \mathrm{C}$ overnight. On the next day, the protein was eluted three times with $0.1 \%$ PBST, resuspended in 2x SDS-PAGE loading buffer, and boiled for $5 \mathrm{~min}$. The eluate was fractionated by SDS-PAGE.

Western blot analysis. DU-145, PC-3 and RWPE- 1 cells were grown in T-75 flasks at $5 \times 10^{6}$ cells $/ \mathrm{mL}$ and DU-145 cells were treated with vehicle or the specified YK-2-69 concentration for $72 \mathrm{~h}$, and treated cells were harvested and lysed by sonication in receptor lysis buffer (RLB) containing $20 \mathrm{mM} \mathrm{HEPES} \mathrm{(pH} \mathrm{7.5),}$ $500 \mathrm{mM} \mathrm{NaCl}, 1 \%$ Triton X-100, $1 \mathrm{mM}$ DTT, 10\% glycerol, phosphatase inhibitors (50 mM NaF, $1 \mathrm{mM}$ $\mathrm{Na}_{2} \mathrm{VO}_{4}$ ), and protease inhibitor mix (Roche). Lysates were quantitated and 20 to $50 \mu \mathrm{g}$ of protein lysates were boiled in SDS sample buffer, size fractionated by SDS-PAGE, and transferred onto a PVDF membrane (Immobilon). After blocking in 5\% nonfat dry milk (or 3\% BSA), membranes were incubated with the following primary antibodies overnight: Rb mouse monoclonal antibody (1:2000), Phospho-Rb 
rabbit monoclonal antibody (1:1000), CDK4 rabbit monoclonal antibody (1:1000), CDK6 mouse monoclonal antibody (1:2000), DYRK2 rabbit monoclonal antibody (1:1000), PARP rabbit monoclonal antibody (1:1000), RRS1 rabbit polyclonal antibody (1:1000), P21 rabbit monoclonal antibody (1:1000), P27 rabbit monoclonal antibody (1:1000), P53 rabbit polyclonal antibody (1:1000), c-MYC rabbit polyclonal antibody (1:1000), Phospho-c-MYC rabbit monoclonal antibody (1:1000), GAPDH mouse monoclonal antibody (1:20000), Vinculin rabbit polyclonal antibody (1:1000), Beta Tubulin mouse monoclonal antibody (1:3000). Following three washes in PBS-T, the blots were incubated with horseradish peroxidase-conjugated secondary antibody. Proteins were detected by electrochemiluminescence (Thermo Fisher Scientific, USA) and analyzed by Image $\mathrm{J}$ software.

Colony formation assays. Colony formation assays were performed with $5 \times 10^{2}$ cells, which were plated to a 24-well plate. Two weeks after initial plating, cells were fixed, stained with $0.1 \%$ crystal violet, and counted.

Migration and invasion assays. Cells were treated with vehicle or different concentrations $(2,4$ and $8 \mu \mathrm{M})$ of YK-2-69 for $48 \mathrm{~h}$, and equal numbers $\left(2 \times 10^{4}\right.$ cells per well) of the cells were seeded in FBS-free RPMI1640 culture medium in the presence of vehicle or different concentrations of YK2-69 in the upper chambers of transwell inserts with an 8-mm pore size. The lower chambers were filled with $500 \mu \mathrm{L}$ of medium supplemented with 10\% FBS. Cells were allowed to invade the bottom chamber for $24 \mathrm{~h}$. Noninvading or non-migrating cells in the upper surface were removed, and invaded or migrated cells on the lower surface were fixed with $4 \%$ paraformaldehyde and stained with $0.1 \%$ crystal violet for $5 \mathrm{~min}$. The stained cells were photographed and quantified.

Cell cycle and apoptosis assays. In this study, propidium iodide (PI) DNA staining was chosen to assess the cells located at G0/G1, S, and G2/M stages. For PI staining, $1 \times 10^{6}$ cells were collected, washed once with PBS, $70 \%$ ethanol was added, gently beaten, fixed at $4{ }^{\circ} \mathrm{C}$ for $12 \mathrm{~h}$, centrifuged at $1000 \mathrm{~g}$ for 5 min, and the cells were precipitated. Carefully suck out the supernatant and add $1 \mathrm{~mL}$ PBS and suspended in $0.5 \mathrm{~mL}$ Krishan's buffer supplemented with $0.05 \mathrm{mg} / \mathrm{mL}$ PI, $0.1 \%$ trisodium citrate, $0.02 \mathrm{mg} / \mathrm{mL}$ ribonuclease $\mathrm{A}$, and $0.3 \% \mathrm{NP}-40$, incubated at $37{ }^{\circ} \mathrm{C}$ for $30 \mathrm{~min}$ and then applied to flow cytometer directly. The samples were transferred onto ice before subjected to flow cytometry. Cell apoptosis was assayed by annexin V-FITC and PI. Cells were seeded at $1 \times 10^{6}$ /well in 10\% FBS-RPMI1640 into six-well plates and treated with test compounds for $24 \mathrm{~h}$. The cells were then washed twice with cold PBS and resuspended in 1 xbinding buffer (0.1 M HEPES ( $\left.\mathrm{pH} 7.4), 1.4 \mathrm{M} \mathrm{NaCl}, 25 \mathrm{mM} \mathrm{CaCl}_{2}\right)$ at a concentration of $1 \times 10^{6}$ cells $/ \mathrm{mL}$. A $100 \mu \mathrm{L}$ volume of the solution ( $1 \times 10^{5}$ cells) was transferred to a $5 \mathrm{~mL}$ culture tube; 5 $\mu \mathrm{L}$ of FITC-Annexin V (BD, Pharmingen) and $5 \mu \mathrm{L}$ PI were added to each tube. The cell suspension was gently vortexed and incubated for $30 \mathrm{~min}$ at room temperature $\left(25^{\circ} \mathrm{C}\right)$ in the dark, and then $200 \mu \mathrm{L}$ PBS was added to each tube. The apoptosis assay was carried out by flow cytometry (FACSVerse, BD, USA) at $488 \mathrm{~nm}$ excitation and the results were analyzed with FlowJo V10 software.

Structure-based virtual screening. The co-crystal structure of DYRK2 and LDN192960 was downloaded from RCSB Protein Data Bank (PDB code: $6 \mathrm{KOJ}$ ), then the disordered conformations, crystal water, and 
ligand in the co-crystal were removed. Next, protein was prepared by Prepare protein protoco/ in Discovery Studio (DS) 2020 and then the binding site of $6 \mathrm{KOJ}$ was defined form PDB site records for further docking. Compounds of the Specs database (221,097 compounds) and in-house library $(3,200$ compounds) were first filtered based on Lipinski's rule of five, Veber's rule and pan assay interference compounds and then the remaining 195,483 compounds were subjected to structure-based virtual screening (DYRK2 PDB: 6KOJ) via the Libdock protocol of DS2020. Next, the 9,696 ligands with a LibDock score of more than 125 were subjected to structure-based virtual screening via the CDOCKER protocol of DS2020. The 2,724 ligands with a "- CDOCKER INTERACTION ENERGY" of more than 55 were further clustered into 100 clusters by Find Diverse Molecules of DS2020. The 15 compounds (Figure S2) were selected through visual inspection and then validated in the DYRK2 inhibitory activity.

\section{$I_{50}$ determination and kinase-inhibitor specificity profiling. Purified DYRK1A, DYRK1B, DYRK2, DYRK3} and DYRK4 protein were diluted to $10 \mathrm{mU}$ in $50 \mathrm{mM}$ Tris- $\mathrm{HCl}(\mathrm{pH} 7.5), 0.1 \mathrm{mM}$ EGTA, 0.1\% $\beta$ mercaptoethanol. A final volume of $25 \mu \mathrm{L}$ kinase reaction buffer was constituted by base reaction buffer (20 mM HEPES (pH 7.5), 10 mM MgCl 2,1 mM EGTA, 0.02\% Brij35, 0.02 mg/mL BSA, $0.1 \mathrm{mM} \mathrm{Na}_{3} \mathrm{VO}_{4}, 2$ mM DTT, 1\% DMSO), 0.05 mM [33P-yATP] (10 Ci/L), $300 \mu \mathrm{M}$ Woodtide (KKISGRLSPIMTEQ) substrate peptide and $10 \mathrm{mU}$ DYRK2 protein. Tested compounds were serially diluted in DMSO with final concentration ranging from $0.1 \mathrm{nM}$ to $10 \mu \mathrm{M}$ and delivered to reaction mixture. The kinase reaction was allowed to run in room temperature for $3 \mathrm{~h}$. The radioactivity was detected by filter-binding method. Kinase activity data were expressed as the percent remaining kinase activity in test samples compared to vehicle (DMSO). $I C_{50}$ values and curve fits were obtained using GraphPad Prism 8.0 software.

Kinase inhibitor specificity profiling assays were carried out at Reaction Biology Corporation. YK-2-69 kinase specificity was determined against a panel of 370 protein kinases at the concentration $1 \mu \mathrm{M}$. The results are presented as an average of duplicate reactions.

Acute toxicity studies. To study the safety in vivo, seven-week ICR mice (weight 18 - $22 \mathrm{~g}$ ), half male and half female, were randomly divided into one control group and three treatment groups ( $n=10 /$ group). Mice of treatment groups were administrated by oral at a dose of 2,500,5,000, and 10,000 mg/kg, respectively. After one dose, the signs of toxicity were observed, and body weight was recorded once two days in 14 days.

Pharmacokinetic profiles. SD rats were used to determine the pharmacokinetic profiles of YK-2-69. SD rats were divided into intravenous and oral administration groups ( $n=3 /$ group). The dose of intravenous and oral administration group was 1 and $10 \mathrm{mg} / \mathrm{kg}$, respectively. Blood samples of intravenous group were collected at $2 \mathrm{~min}, 5 \mathrm{~min}, 15 \mathrm{~min}, 30 \mathrm{~min}, 1 \mathrm{~h}, 2 \mathrm{~h}, 4 \mathrm{~h}, 6 \mathrm{~h}, 8 \mathrm{~h}$, and $12 \mathrm{~h}$. and blood samples of oral administration group were collected at $5 \mathrm{~min}, 15 \mathrm{~min}, 30 \mathrm{~min}, 1 \mathrm{~h}, 2 \mathrm{~h}, 4 \mathrm{~h}, 6 \mathrm{~h}, 8 \mathrm{~h}, 12 \mathrm{~h}$, and $24 \mathrm{~h}$. The concentrations of YK-2-69 in serum were measured by LC/MS/MS.

In vivo antitumor activity. BABLc nude mice received subcutaneous injection of $1 \times 10^{7}$ DU-145 shVehicle cells and DU-145 KD cells in the right flank to establish shVehicle group ( $n=6 /$ group) and shDYRK2 
group ( $n=10 /$ group), respectively. Tumor volumes and body weight were measured once two days. After 29 days, the shVehicle group mice were sacrificed for humane reasons, and tumor issues were weighed and taken photos. After 49 days, shDYRK2 group mice were sacrificed, and tissues were weighed and taken photos. Tumor tissues of each group were kept in $-80^{\circ} \mathrm{C}$ for further analysis.

BABLc nude mice received subcutaneous injection of $1 \times 10^{7}$ DU-145 cells in the right flank. When the average tumors reached the volumes of $100-150 \mathrm{~mm}^{3}$, the mice were randomly divided into control $(\mathrm{n}=$ $10 /$ group), drug treatment groups ( $n=10 /$ group). YK-2-69 at doses of 100 and $200 \mathrm{mg} / \mathrm{kg}$ were given by oral every day. Palbociclib and enzalutamide were given to mice by oral at a dosage of $100 \mathrm{mg} / \mathrm{kg} / \mathrm{d}$ and used as positive references for comparison, while control mice received the equal volume of saline.

Tumor volumes and body weight were measured once two days. After 35 days, the mice in control group were sacrificed for humane reasons, and tumor issues were weighed and taken photos. After 49 days, mice of treatment groups were sacrificed, and tissues were weighed and taken photos. Tumor tissues of each group were kept in $-80^{\circ} \mathrm{C}$ for further analysis.

H\&E and Ki67 Staining. Tumor tissues and normal tissues were fixed in $4 \%$ formaldehyde solution and processed routinely for paraffin embedding. Sections were cut at around $4 \mu \mathrm{m}$ thickness and placed on glass slides, and counterstained with hematoxylin and eosin and anti-Ki-67.

RNA-seq sequencing. Total RNA samples were isolated from the YK-2-69 treated and DYRK2-KD cells respectively. RNA concentration was measured by NanoDrop 1000 (Thermo Fisher Scientific, Waltham, MA, USA), and RNA integrity was measured by BioAnalyzer (Agilent). According to Life Technologies guidelines, adding an appropriate amount of MIX1 or MIX2 to each RNA sample will result in approximately $1 \%$ of the total RNA-seq readings mapped to the 92 ERCC control sequences, assuming that the mRNA fragments are located at $2 \%$ of the total RNA. Using the Kapa chain mRNA-seq kit (Illumina) (Kapa Biosystems, Wilmington, USA), a library of $300 \mathrm{ng}$ total RNA was constructed for each sample through 10 PCR amplification cycles. The library was purified using the AxyPrep MAG PCR purification kit (Thermo Fisher Scientific). Each library was quantified using a Qubit fluorometer (Life Technologies) and assessed for size distribution using 2100 BioAnalyzer (Agilent Technologies, Santa Clara, USA). Sequencing was performed using Truseq SR Cluster Kit V4-CBOt-HS (Illumina) on Illumina HiSeq 2500 (Illumina, San Diego, CA, USA) apparatus with a V4 chemically generated 51 bp single-ended read sequence. Each group contains 3-4 repeats and the corresponding control group keep the same number of repeats. Quality control of RNA-Seq reads was performed using FASTQC. The reads with low complexity or low quality were removed using Cutadapt. Trimmed reads were aligned to human genome reference (GRCh38) using STAR, and uniquely mapped reads were retained in the downstream analysis. RSEM was used to calculate the expression levels of genes. Differentially expressed gene (DEG) analysis was performed using DESeq2, $\mathrm{P}<0.05$ and 1.5 -fold change was used as statistical significance. The IGV was used to show the distribution of readings in a particular transcript. Hierarchical clustering analysis was performed using R package 'mclust'. Genome Set Enrichment Analysis (GSEA) were employed to calculate enrichment pathways based on the signature gene sets from the Molecular Biology Database (MSIGDB). 


\section{Synthesis of DYRK2 Inhibitors}

General Methods. All chemicals were used as received without further purification unless stated otherwise. ${ }^{1} \mathrm{H}$ and ${ }^{13} \mathrm{C}$ NMR spectra were collected on BRUKER AV-300 or BRUKER AV-400 or BRUKER AV500 spectrometer. Chemical shifts downfield from TMS, an internal standard, are shown in parts per million (ppm, $\delta$ ). High Resolution Mass measurement was performed on Agilent QTOF 6520 mass spectrometer with electron spray ionization (ESI) as the ion source. Flash column chromatography was carried out using commercially available 200-300 mesh silica gel under pressure. The final compounds were analyzed with a Shimadzu 2020 series HPLC system using an Inertsil ODS-3 column $(5 \mu \mathrm{m}, 4.6 \times$ $100 \mathrm{~mm}$ ) with a solvent system consisting of $\mathrm{H}_{2} \mathrm{O}$ (mobile phase $A$ ) and $\mathrm{MeOH}$ (mobile phase $\mathrm{B}$ ), and the purity of all the final compounds was found to be $>95 \%$.
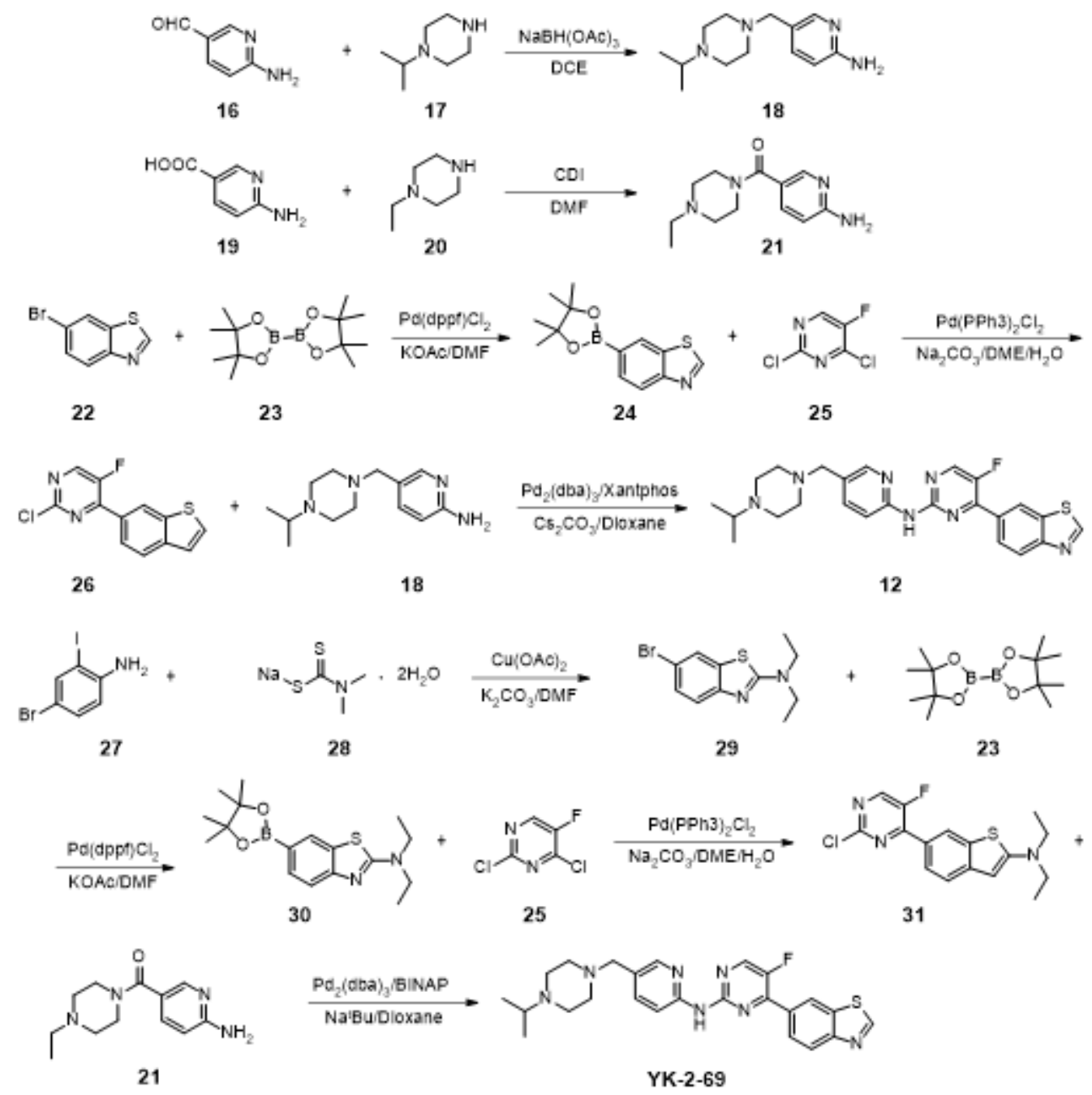

Synthesis of compound 12 and YK-2-69

5-((4-Isopropylpiperazin-1-yl)methyl)pyridin-2-amine (18)

The mixture of 6-aminonicotinaldehyde $16(0.61 \mathrm{~g}, 5 \mathrm{mmol})$ and 1-isopropylpiperazine $17(0.96 \mathrm{~g}, 7.5$ $\mathrm{mmol})$ in 1, 2-dichloroethane $(40 \mathrm{~mL})$ was stirred at room temperature for $2 \mathrm{~h}$. Then $\mathrm{NaBH}(\mathrm{OAc})_{3}(2.12 \mathrm{~g}$, 
$10 \mathrm{mmol}$ ) was added to the mixture and stirred at room temperature for $8 \mathrm{~h}$. The reaction mixture was quenched by adding $1 \mathrm{M} \mathrm{NaOH}(50 \mathrm{~mL})$ solution and extracted with $\mathrm{DCM}(40 \mathrm{~mL})$ for three times. The DCM extract was dried by anhydrous $\mathrm{Na}_{2} \mathrm{SO}_{4}$ and the solvent was evaporated under reduced pressure. The residue was purified by chromatography on silica to provide $18(0.95 \mathrm{~g}, 81 \%)$ as a white solid. ${ }^{1} \mathrm{H}$ $\operatorname{NMR}\left(400 \mathrm{MHz}, \mathrm{CDCl}_{3}\right) \delta 7.88(\mathrm{~d}, J=2.2 \mathrm{~Hz}, 1 \mathrm{H}), 7.43(\mathrm{dd}, J=8.4,2.2 \mathrm{~Hz}, 1 \mathrm{H}), 6.48(\mathrm{~d}, J=8.4 \mathrm{~Hz}, 1 \mathrm{H})$, $4.95(\mathrm{~s}, 2 \mathrm{H}), 3.39(\mathrm{~s}, 2 \mathrm{H}), 2.88-2.80(\mathrm{~m}, 1 \mathrm{H}), 2.72-2.51(\mathrm{~m}, 8 \mathrm{H}), 1.10(\mathrm{~d}, J=6.6 \mathrm{~Hz}, 6 \mathrm{H})$.

(6-Aminopyridin-3-yl)(4-ethylpiperazin-1-yl)methanone (21)

The mixture of 6-aminonicotinic acid $19(0.28 \mathrm{~g}, 2 \mathrm{mmol})$ and $\mathrm{N}, \mathrm{N}$-carbonyldiimidazole $(0.39 \mathrm{~g}, 2.4$ $\mathrm{mmol})$ in DMF $(5 \mathrm{~mL})$ was stirred at $70{ }^{\circ} \mathrm{C}$ for $10 \mathrm{~min}$, then the mixture was stirred at room temperature. After $1 \mathrm{~h}$, 1-ethylpiperazine $\mathbf{2 0}(0.46 \mathrm{~g}, 4.0 \mathrm{mmol})$ was added to the mixture and the mixture was stirred at room temperature overnight. The solvent was evaporated under reduced pressure and the residue was purified by chromatography on silica to provide $21(0.40 \mathrm{~g}, 81 \%)$ as a white solid. ${ }^{1} \mathrm{H}$ NMR $(300 \mathrm{MHz}$, $\left.\mathrm{CDCl}_{3}\right) \delta 8.19-8.17(\mathrm{~m}, 1 \mathrm{H}), 7.57-7.54(\mathrm{~m}, 1 \mathrm{H}), 6.51-6.48(\mathrm{~m}, 0.9 \mathrm{~Hz}, 1 \mathrm{H}), 4.79(\mathrm{~s}, 2 \mathrm{H}), 3.73-3.60$ $(\mathrm{m}, 4 \mathrm{H}), 2.49-2.42(\mathrm{~m}, 6 \mathrm{H}), 1.13-1.08(\mathrm{~m}, 3 \mathrm{H})$.

\section{6-(4,4,5,5-Tetramethyl-1,3,2-dioxaborolan-2-yl)benzo[d]thiazole (24)}

The mixture of 6-Bromobenzo[d]thiazole 22 (0.43 g, $2.0 \mathrm{mmol}), 4,4,4^{\prime}, 4^{\prime}, 5,5,5^{\prime}, 5^{\prime}$-octamethyl-2,2'-bi(1,3,2dioxaborolane) 23 (0.53 g, $2.1 \mathrm{mmol}), \mathrm{Pd}(\mathrm{dppf}) \mathrm{Cl}_{2}(22 \mathrm{mg}, 0.06 \mathrm{mmol})$, and $\mathrm{KOAc}(0.59 \mathrm{~g}, 6.0 \mathrm{mmol})$ in DMF $(10 \mathrm{~mL})$ was stirred at $80{ }^{\circ} \mathrm{C}$ under Ar atmosphere. After $24 \mathrm{~h}$, the mixture was filtered by diatomite, and the filtrate was evaporated under reduced pressure. The residue was purified by chromatography on silica to afford $24(0.47 \mathrm{~g}, 90 \%)$ as a white solid. ${ }^{1} \mathrm{HNMR}\left(300 \mathrm{MHz}, \mathrm{CDCl}_{3}\right) \delta 9.07(\mathrm{~s}, 1 \mathrm{H}), 8.46(\mathrm{~s}, 1 \mathrm{H})$, $8.14(\mathrm{~d}, J=8.2 \mathrm{~Hz}, 1 \mathrm{H}), 7.94$ (dd, $J=8.2,1.1 \mathrm{~Hz}, 1 \mathrm{H}), 1.38(\mathrm{~s}, 12 \mathrm{H})$.

\section{6-(2-Chloro-5-fluoropyrimidin-4-yl)benzo[d]thiazole (26)}

The mixture of 2,4-dichloro-5-fluoropyrimidine 25 (0.23 g, $1.4 \mathrm{mmol}), \mathrm{Pd}\left(\mathrm{PPh}_{3}\right)_{2} \mathrm{Cl}_{2}(21 \mathrm{mg}, 0.03 \mathrm{mmol})$, $\mathrm{Na}_{2} \mathrm{CO}_{3}(0.27 \mathrm{~g}, 2.5 \mathrm{mmol}), \mathrm{DME}(10 \mathrm{~mL})$, and $\mathrm{H}_{2} \mathrm{O}(0.25 \mathrm{~mL})$ were stirred at $80{ }^{\circ} \mathrm{C}$ in three-neck flask under Ar atmosphere. Compound $\mathbf{2 4}(0.26 \mathrm{~g}, 1.0 \mathrm{mmol})$ dissolved in the DME (5 mL) was added to the mixture dropwise. After $16 \mathrm{~h}$, the mixture was filtered by diatomite and the filtrate was evaporated under reduced pressure. The residue was purified by chromatography on silica to provide $\mathbf{2 6}(0.22 \mathrm{~g}, 82 \%)$ as a white solid. ${ }^{1} \mathrm{HNMR}\left(300 \mathrm{MHz}, \mathrm{CDCl}_{3}\right) \delta 9.17(\mathrm{~s}, 1 \mathrm{H}), 8.84(\mathrm{~d}, J=1.7 \mathrm{~Hz}, 1 \mathrm{H}), 8.58(\mathrm{~d}, J=3.1 \mathrm{~Hz}, 1 \mathrm{H}), 8.37$ $-8.24(\mathrm{~m}, 2 \mathrm{H})$.

4-(Benzo[d]thiazol-6-yl)-5-fluoro-N-(5-((4-isopropylpiperazin-1-yl)methyl)pyridin-2-yl)pyrimidin-2-amine (12)

The mixture of compound 26 (133 mg, $0.5 \mathrm{mmol})$, compound 18 (141 mg, $0.6 \mathrm{mmol}), \mathrm{Pd}_{2}(\mathrm{dba})_{3}(23 \mathrm{mg}$, $0.025 \mathrm{mmol})$, Xantphos (58 mg, $0.1 \mathrm{mmol}), \mathrm{Cs}_{2} \mathrm{CO}_{3}(326 \mathrm{mg}, 1.0 \mathrm{mmol})$, and dioxane $(5 \mathrm{~mL})$ was stirred at $100{ }^{\circ} \mathrm{C}$ in the sealing tube under Ar atmosphere. The mixture was filtered by diatomite after $12 \mathrm{~h}$, and 
the filtrate was evaporated under reduced pressure. The residue was purified by chromatography on silica to provide $10(111 \mathrm{mg}, 48 \%)$ as a white solid. ${ }^{1} \mathrm{H} \mathrm{NMR}(400 \mathrm{MHz}, \mathrm{CDCl} 3) \delta 9.15(\mathrm{~s}, 1 \mathrm{H}), 8.78(\mathrm{~d}, J=1.6 \mathrm{~Hz}$, $1 \mathrm{H}), 8.48(\mathrm{~d}, J=3.5 \mathrm{~Hz}, 1 \mathrm{H}), 8.38(\mathrm{dd}, J=8.5,0.8 \mathrm{~Hz}, 1 \mathrm{H}), 8.35-8.32(\mathrm{~m}, 1 \mathrm{H}), 8.30-8.27(\mathrm{~m}, 1 \mathrm{H}), 8.25-$ $8.23(\mathrm{~m}, 2 \mathrm{H}), 7.73(\mathrm{dd}, J=8.6,2.3 \mathrm{~Hz}, 1 \mathrm{H}), 3.50(\mathrm{~s}, 2 \mathrm{H}), 2.68-2.44(\mathrm{~m}, 9 \mathrm{H}), 1.06(\mathrm{~d}, J=6.5 \mathrm{~Hz}, 6 \mathrm{H})$. HRMS (ESI) for $\mathrm{C}_{24} \mathrm{H}_{26} \mathrm{FN}_{7} \mathrm{~S}[\mathrm{M}+\mathrm{H}]^{+}$: calcd. 464.2027; found, 464.2016

\section{6-Bromo-N,N-dimethylbenzo[d]thiazol-2-amine (29)}

The mixture of 4-bromo-2-iodoaniline $27(0.60 \mathrm{~g}, 2.0 \mathrm{mmol})$, sodium dimethyldithiocarbamate 28 ( $0.72 \mathrm{~g}$, $4.0 \mathrm{mmol}), \mathrm{Cu}(\mathrm{OAc})_{2}(0.36 \mathrm{~g}, 2.0 \mathrm{mmol}), \mathrm{K}_{2} \mathrm{CO}_{3}(58 \mathrm{mg}, 0.1 \mathrm{mmol})$ in $\mathrm{DMF}(10 \mathrm{~mL})$ was stirred at $120{ }^{\circ} \mathrm{C}$. The mixture was filtered by diatomite after $12 \mathrm{~h}$, and the filtrate was evaporated under reduced pressure. The residue was purified by chromatography on silica to provide $29(0.44 \mathrm{~g}, 85 \%)$ as a white solid. ${ }^{1} \mathrm{H}$ $\operatorname{NMR}\left(400 \mathrm{MHz}, \mathrm{CDCl}_{3}\right) \delta 7.69(\mathrm{~d}, J=1.9 \mathrm{~Hz}, 1 \mathrm{H}), 7.41-7.35(\mathrm{~m}, 2 \mathrm{H}), 3.20(\mathrm{~s}, 6 \mathrm{H})$.

N,N-Dimethyl-6-(4,4,5,5-tetramethyl-1,3,2-dioxaborolan-2-yl)benzo[d]thiazol-2-amine (30)

The synthetic procedure for compound $\mathbf{3 0}$ is similar to that of compound $\mathbf{2 4}$ and gave a yield of $88 \%$ as a yellow solid. ${ }^{1} \mathrm{H}$ NMR $(400 \mathrm{MHz}, \mathrm{CDCl} 3) \delta 8.06(\mathrm{~s}, 1 \mathrm{H}), 7.73(\mathrm{~d}, J=7.8 \mathrm{~Hz}, 1 \mathrm{H}), 7.54(\mathrm{~d}, J=7.8 \mathrm{~Hz}, 1 \mathrm{H})$, $3.22(\mathrm{~s}, 6 \mathrm{H}), 1.35(\mathrm{~s}, 12 \mathrm{H})$.

6-(2-Chloro-5-fluoropyrimidin-4-yl)-N,N-dimethylbenzo[d]thiazol-2-amine (31)

The synthetic procedure for compound $\mathbf{3 1}$ is similar to that of compound $\mathbf{2 6}$ and gave a yield of $80 \%$ as a yellow solid. ${ }^{1} \mathrm{H}$ NMR $\left(400 \mathrm{MHz}, \mathrm{CDCl}_{3}\right) \delta 8.49(\mathrm{~d}, J=1.9 \mathrm{~Hz}, 1 \mathrm{H}), 8.45(\mathrm{~d}, J=3.6 \mathrm{~Hz}, 1 \mathrm{H}), 8.17-8.14(\mathrm{~m}$, $1 \mathrm{H}), 7.62(\mathrm{~d}, J=8.7 \mathrm{~Hz}, 1 \mathrm{H}), 3.27(\mathrm{~s}, 6 \mathrm{H})$.

(6-((4-(2-(Dimethylamino)benzo[d]thiazol-6-yl)-5-fluoropyrimidin-2-yl)amino)pyridin-3-yl)(4isopropylpiperazin-1-yl)methanone (YK-2-69)

The mixture of compound 31 (154 mg, $0.5 \mathrm{mmol}), 21$ (141 mg, $0.6 \mathrm{mmol}), \mathrm{Pd}_{2}(\mathrm{dba})_{3}(23 \mathrm{mg}, 0.025$ mmol), BINAP (31 mg, $0.05 \mathrm{mmol}), \mathrm{NaO}{ }^{\mathrm{t}} \mathrm{Bu}(96 \mathrm{mg}, 1.0 \mathrm{mmol})$, and dioxane $(5 \mathrm{~mL})$ was stirred at $100{ }^{\circ} \mathrm{C}$ in the sealing tube under Ar atmosphere. The mixture was filtered by diatomite after $12 \mathrm{~h}$, and the filtrate was evaporated under reduced pressure. The residue was purified by chromatography on silica to provide YK-2-69 (139 mg, 55\%) as a white solid. ${ }^{1} \mathrm{H}$ NMR (400 MHz, DMSO) $\delta 10.27(\mathrm{~s}, 1 \mathrm{H}), 8.68(\mathrm{~d}, J=3.8 \mathrm{~Hz}$, $1 \mathrm{H}), 8.52(\mathrm{~d}, J=2.0 \mathrm{~Hz}, 1 \mathrm{H}), 8.35(\mathrm{~d}, J=2.4 \mathrm{~Hz}, 1 \mathrm{H}), 8.31(\mathrm{~d}, J=8.7 \mathrm{~Hz}, 1 \mathrm{H}), 8.06(\mathrm{~d}, J=8.6 \mathrm{~Hz}, 1 \mathrm{H}), 7.86$ $(\mathrm{dd}, J=8.7,2.4 \mathrm{~Hz}, 1 \mathrm{H}), 7.59(\mathrm{~d}, J=8.6 \mathrm{~Hz}, 1 \mathrm{H}), 3.60-3.48(\mathrm{~m}, 4 \mathrm{H}), 3.21(\mathrm{~s}, 6 \mathrm{H}), 2.40-2.36(\mathrm{~m}, 4 \mathrm{H})$, $1.01(\mathrm{t}, J=7.1 \mathrm{~Hz}, 3 \mathrm{H}) .{ }^{13} \mathrm{C} \mathrm{NMR}\left(151 \mathrm{MHz}, \mathrm{CDCl}_{3}\right) \delta 170.6,168.2,155.8,154.9$ (d, J = 3.1 Hz), 154.0, $152.0(\mathrm{~d}, J=8.8 \mathrm{~Hz}), 151.1$ (d, $J=256.0 \mathrm{~Hz}) 147.5,146.7$ (d, $J=27.1 \mathrm{~Hz}), 137.9,131.8,127.3$ (d, $J=7.5$ $\mathrm{Hz}), 125.6(\mathrm{~d}, J=5.5 \mathrm{~Hz}), 124.6,121.7(\mathrm{~d}, J=7.9 \mathrm{~Hz}), 118.6,111.0,52.2,40.3,11.9$. HRMS (ESI) for $\mathrm{C}_{25} \mathrm{H}_{27} \mathrm{FN}_{8} \mathrm{OS}(\mathrm{M}+\mathrm{H})^{+}$: calcd 507.2085; found, 507.2088. 


\section{Declarations}

\section{Acknowledgements}

This study was supported by National Natural Science Foundation of China (31970547, 82073701, 31900687), Natural Science Foundation of Jiangsu Province (BK20190552, BK20190551) and the Project Program of State Key Laboratory of Natural Medicines, China Pharmaceutical University (SKLNMZZ202013, SKLNMZZRC201808, SKLNMZZ202014 and SKLNMKF202004).

\section{Author contributions}

K. Y. and W. K conceived the project, which had leadership from Y. J., H. H., Y. X. and P. Y. All authors contribute to manuscript writing, review and editing. W. K. and X. W. contribute to TCGA Cancer Genome Atlas data analysis and RNA-seq sequencing. W. K., X. W., M. J., J. L., L. W. and Y. J. contribute to biological experiments, including immunohistochemistry, cell proliferation assays, lentivirus production and infection, real-time quantitative PCR, immunoprecipitation, western blot analysis, soft agar colony formation assays, migration and invasion assays, cell cycle and apoptosis assays. K. Y., W. M. and H. G. contribute to structure-based virtual screening. K. Y., W. C. and P. Y contribute to design and synthesis of DYRK2 inhibitor. Z. L., X. Y., M. L. and Y. X. contribute to crystallography experiments. K. Y., H. H., and P. Y contribute to in vivo acute toxicity studies, pharmacokinetic profiles and antitumor activity experiments. All authors contributed to data analysis and interpretation.

\section{Competing interests}

The authors declare no competing financial interests

\section{Figures}


A

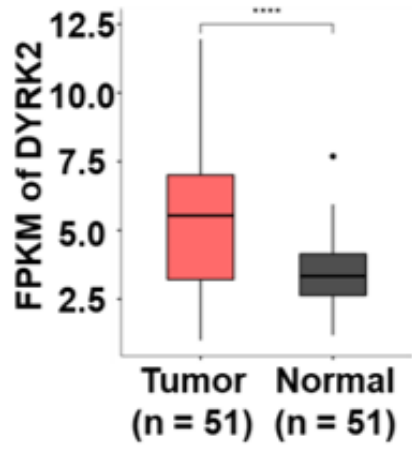

D

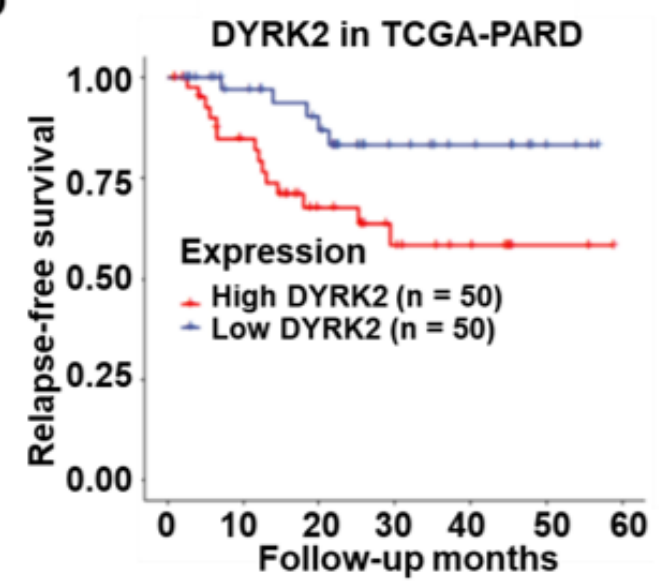

B

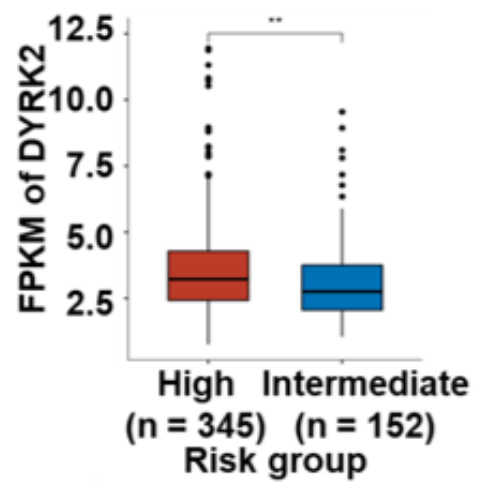

E

C

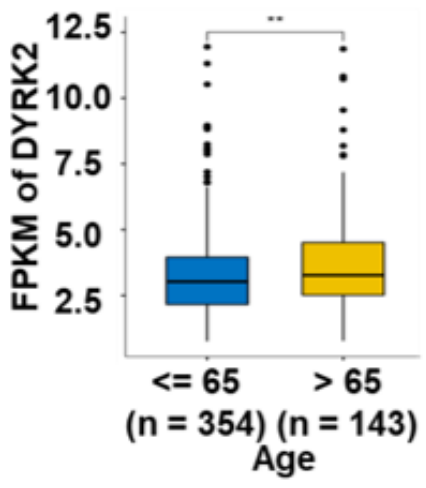

Normal

Prostate cancer

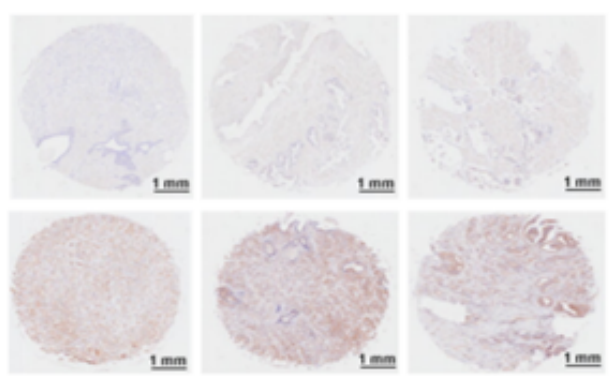

F

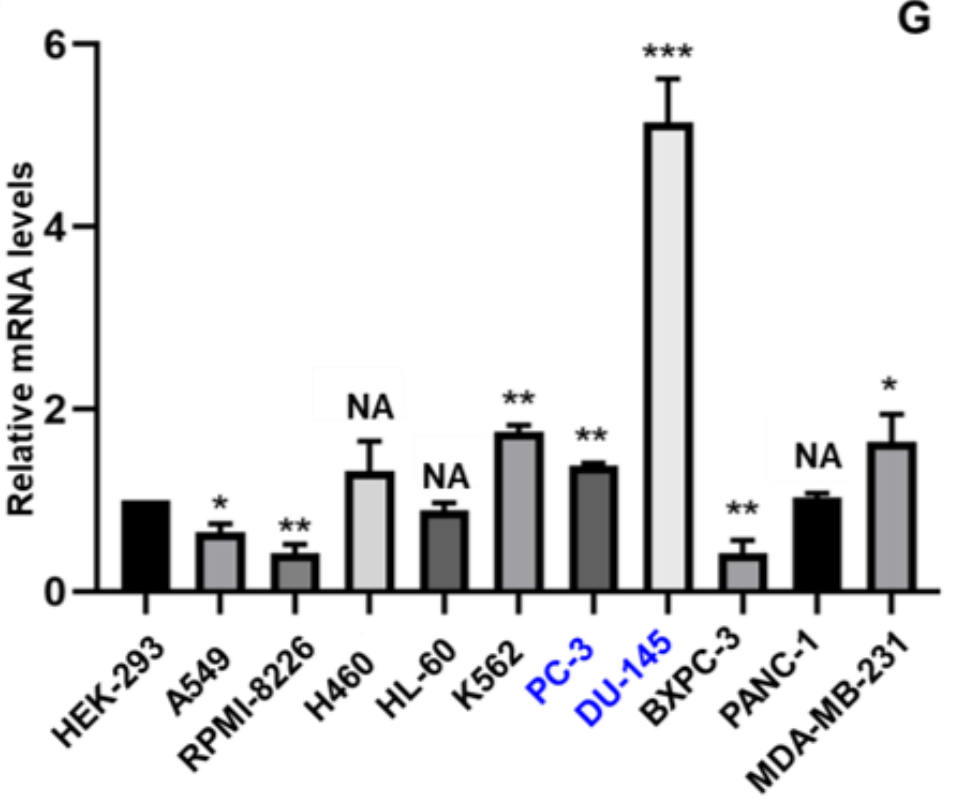

G

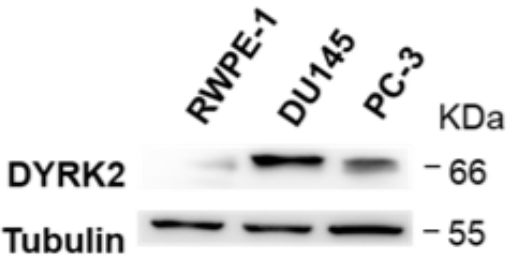

Figure 1

DYRK2 is Highly Expressed in PCa. a, DYRK2 expression in human PCa and matched normal tissue as available from TCGA. b, DYRK2 expression in high and intermediate risk PCa patients as available from TCGA. c, DYRK2 expression in PCa patients below and above the age of 65 as available from TCGA. d, Relapse-free survival of PCa patients with high and low DYRK2 expression as available from TCGA. e, DYRK2 immunohistochemistry of PCa and adjacent normal prostate tissue sections from patients. f, 
mRNA levels of DYRK2 in different cell lines. g, Protein levels of DYRK2 in normal prostate and PCa cell lines. ${ }^{\star} p<0.05 ;{ }^{* \star} p<0.01 ;{ }^{* \star} p<0.001 ;{ }^{* \star \star *} p<0.0001$; unpaired Student's t-test. Error bars, mean $\pm \mathrm{SD}, \mathrm{n}$ $=3$

A

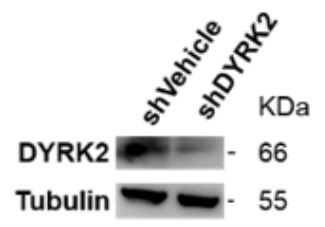

D

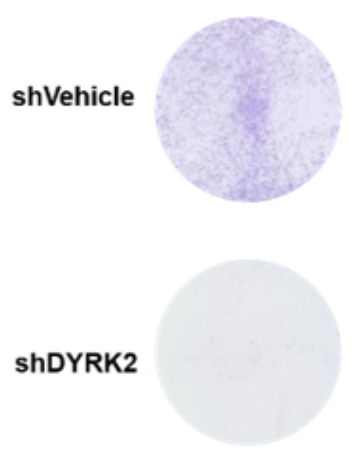

$\mathbf{F}$

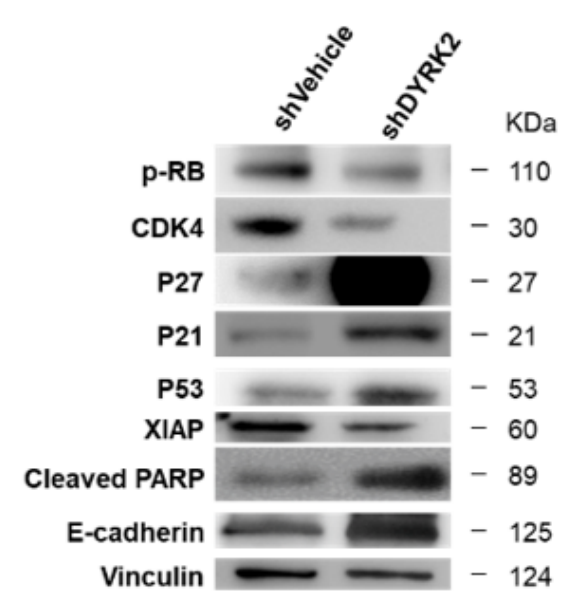

B

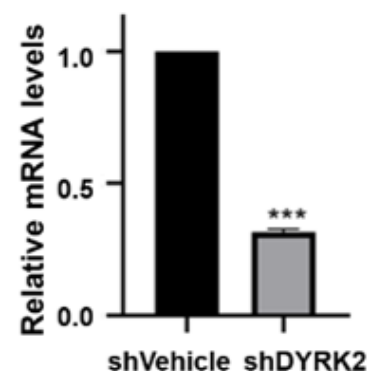

shVehicle shDYRK2

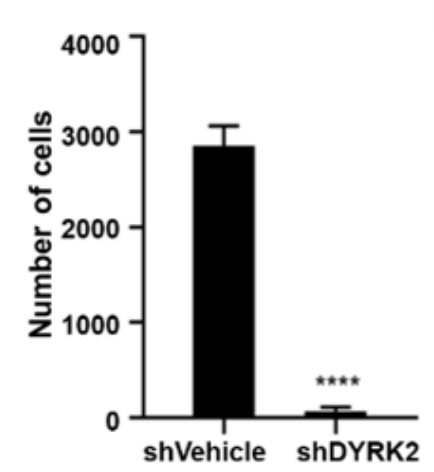

G
C

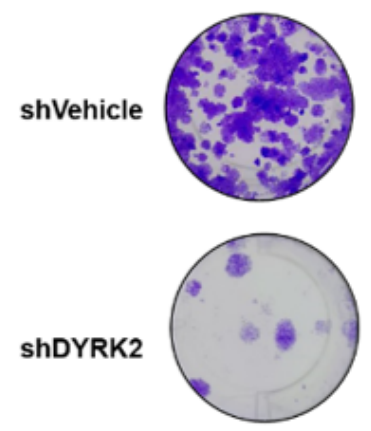

$\mathbf{E}$

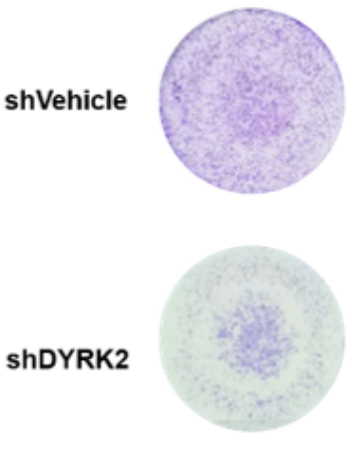

H
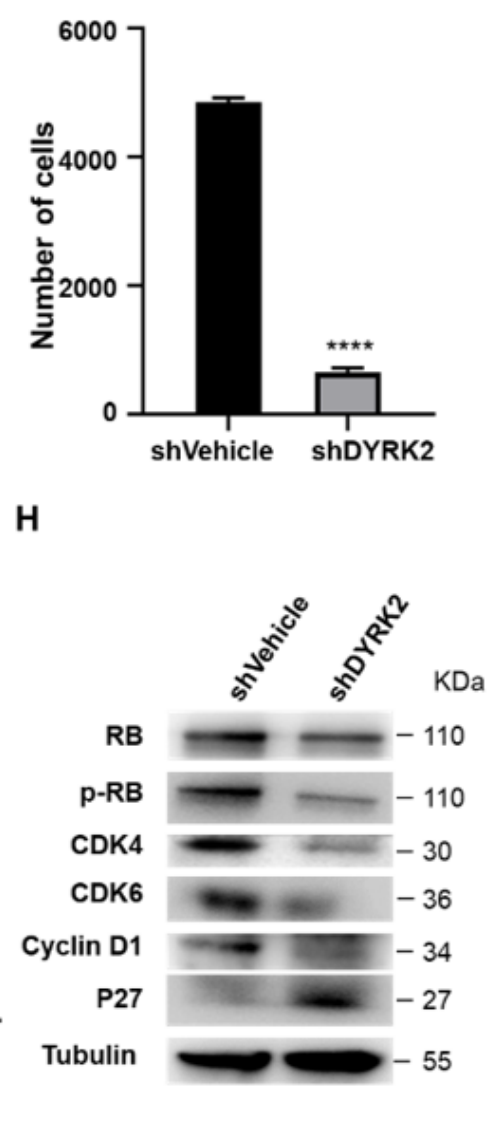

Figure 2

Knock-down of DYRK2 Inhibited PCa in Vitro and in Vivo. a, Protein level of DYRK2 mRNA level of DYRK2 in the DU-145 cells after transfecting with shDYRK2 or shVehicle. b, mRNA level of DYRK2 in the DU-145 cells after transfecting with shDYRK2 or shVehicle. c, Effects of knock-down of DYRK2 on the cell cloning in DU-145 cell lines. d, Effects of knock-down of DYRK2 on the cell migration in DU-145 cell lines. e, Effects of knock-down of DYRK2 on the cell invasion in DU-145 cell lines. $f$, Western blotting analysis of cell cycle and apoptosis related protein changes upon knock-down of DYRK2. g, shDYRK2 and shVehicle DU-145 cells were implanted subcutaneously into nude mice, and tumor volume were measured every two 
days. $h$, Western blotting analysis of cell cycle related protein expression in tumor lysate from mice bearing shDYRK2 and shVehicle DU-145 cell tumor. ${ }^{*} p<0.05 ;{ }^{* \star} p<0.01 ; \star \star \star p<0.001$; ${ }^{* \star \star \star} p<0.0001$; unpaired Student's t-test. Error bars, mean $\pm S D, n=3$.

A

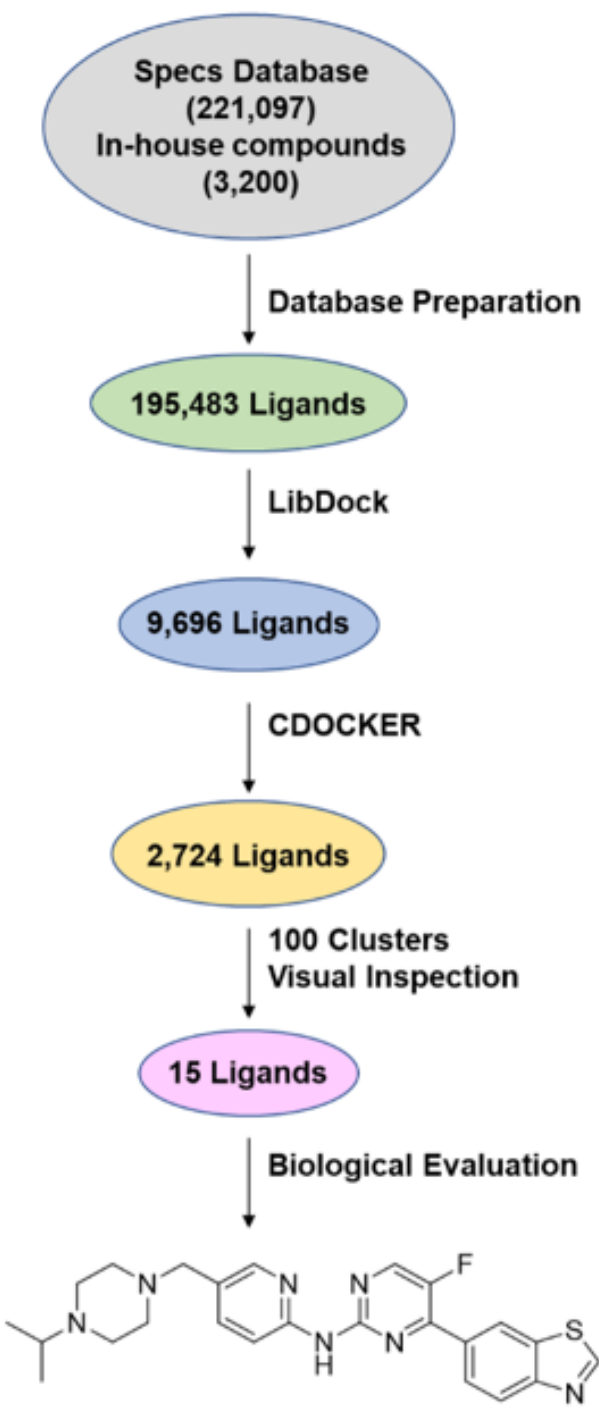

Compound 12

DYRK2 IC I0 $=263 \mathrm{nM}$
C

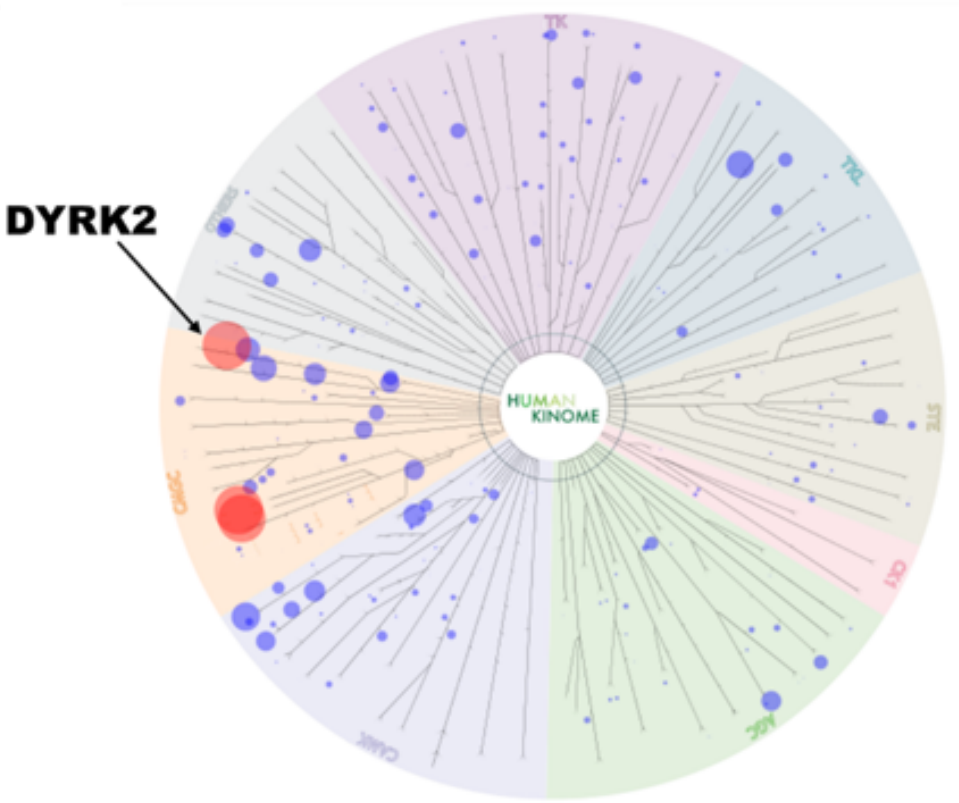

D

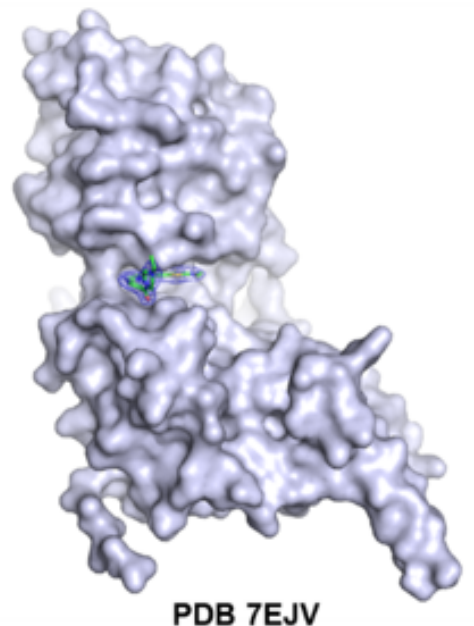

$\mathbf{E}$

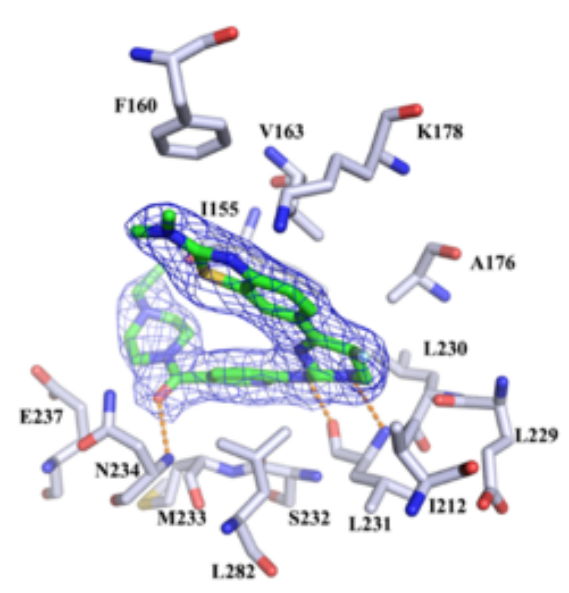

B

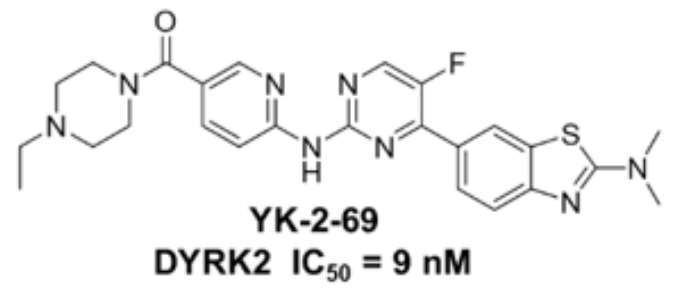

$\mathbf{F}$

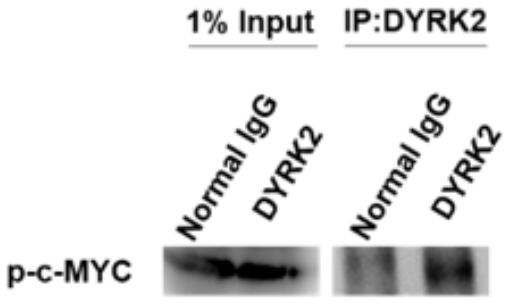

G

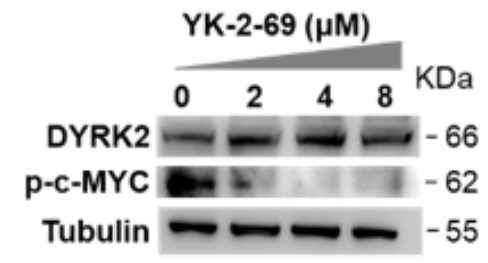

Figure 3

Discovery of the Highly Selective DYRK2 Inhibitor YK-2-69. a, Flowchart of virtual screening to discover the hit DYRK2 inhibitor compound 12. b, Chemical structure of YK-2-69 and inhibitory activity of YK-2-69 
against DYRK2. c, Kinase selectivity of YK-2-69 over 370 kinases. d, Co-crystal structure of YK-2-69 bound to DYRK2. e, Interactions between YK-2-69 and DYRK2 in co-crystal structure. f, Immunoprecipitation assay of p-c-MYC. g, Effect of YK-2-69 treatment on phosphorylation level of c-MYC(Ser62).

A

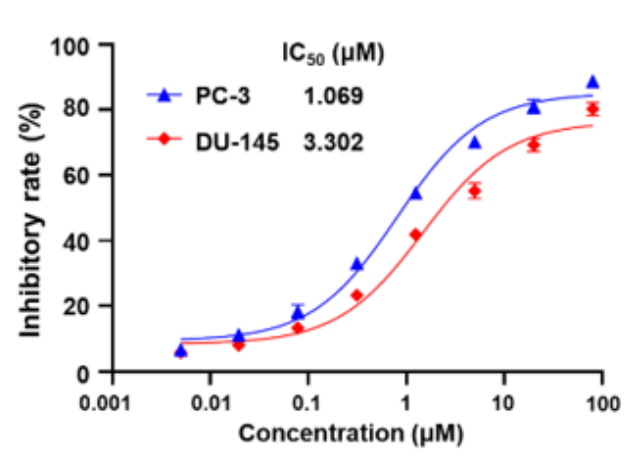

D

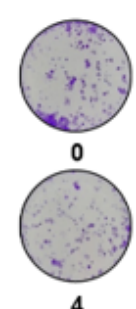

F
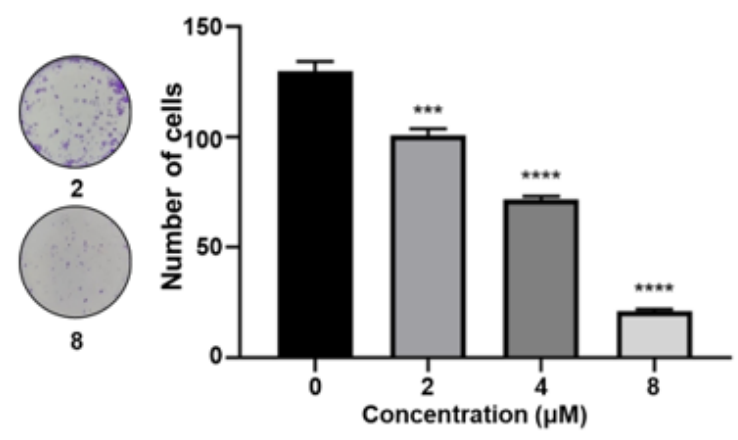

E

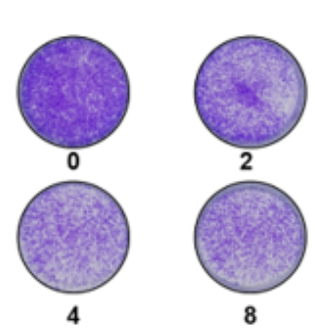

G



C
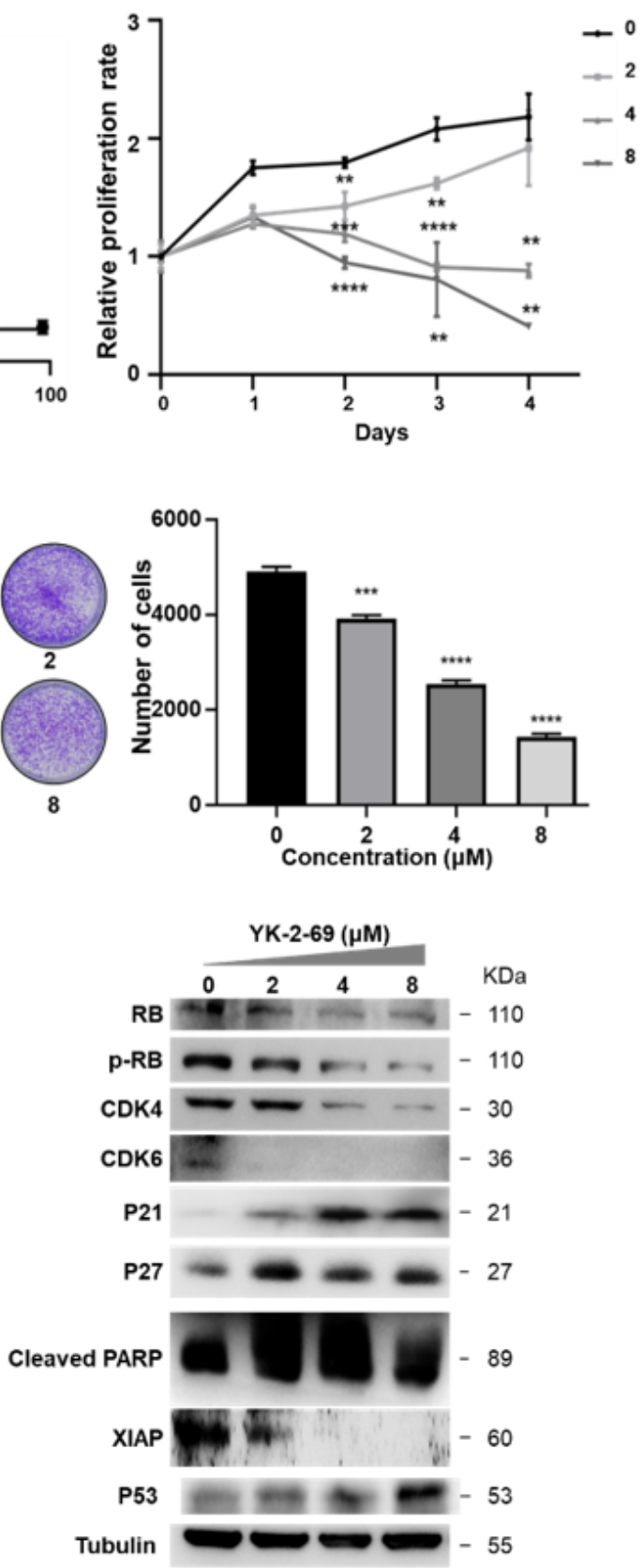

\section{Figure 4}

YK-2-69 Inhibited Cell Growth and Migration and Induced Apoptosis in PCa Cell Lines. a, Effects of YK-269 treatment on proliferation of PC-3 and DU-145 cells. b, Effects of YK-2-69 treatment on proliferation of shDYRK2 DU-145 cells. c, Effect of YK-2-69 treatment on growth of DU-145 cells. d, Effects of YK-2-69 treatment on cell cloning in DU-145 cells. e, Effects of YK-2-69 treatment on cell migration in DU-145 cells. $\mathrm{f}$, Effects of YK-2-69 treatment on cell invasion in DU-145 cells. g, Effects of YK-2-69 treatment on cell 
cycle and apoptosis proteins in DU-145 cells * $p<0.05$; ${ }^{\star *} p<0.01$; ${ }^{* \star} p<0.001$; $* \star \star * p<0.0001$; unpaired Student's t-test. Error bars, mean $\pm \mathrm{SD}, \mathrm{n}=3$

A

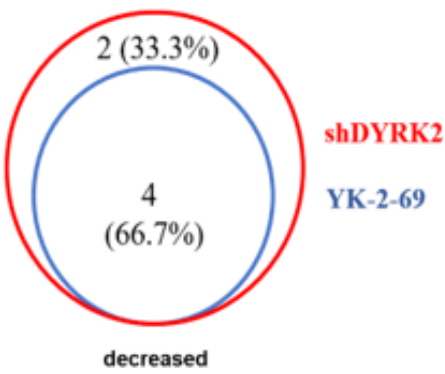

B

C
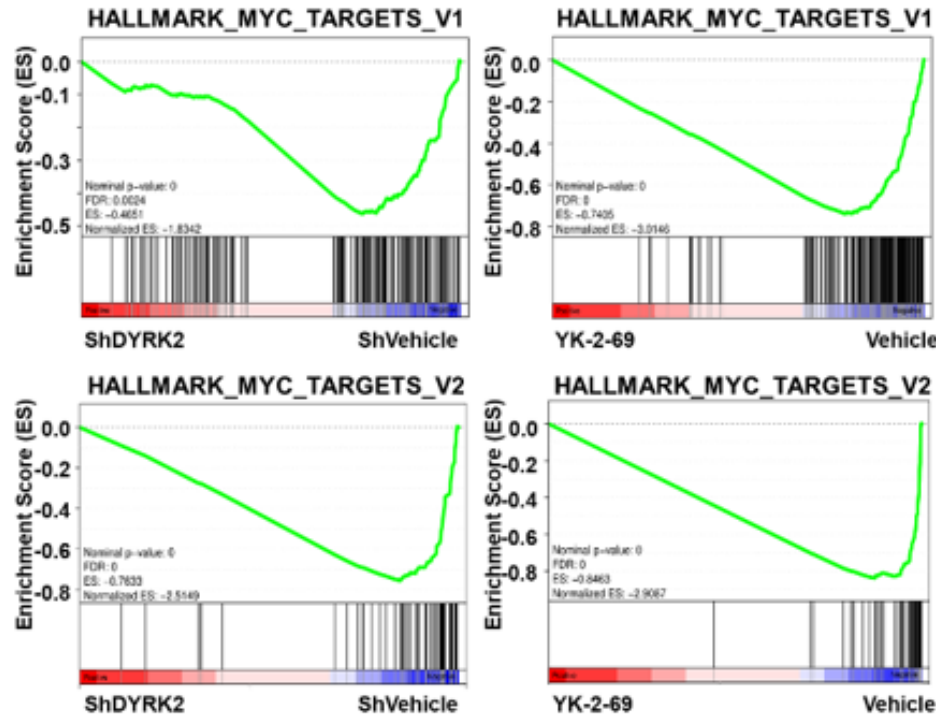

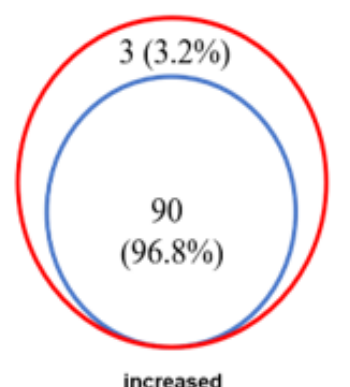

increased
shDYRK2

YK-2-69

HALLMARK_MYC_TARGETS_V HALLMARK_MYC_TARGETS_V1 HALLMARK_UNFOLDED_PROTEIN_RESPONNSE HALLMARK_E2F_TARGETS HALLMARK_EPITHELIAL_MESENCHYMAL_TRANSITION HALLMARK_TNFA_SIGNALING_VIA_NFKB HALLMARK_PI3K_AKT_MTOR_SLGNALING HALLMARK_HYPOXIA HALLMARK_BILE_ACID_METABOLISM HALLMARK_KRAS_SLGNALING_DN
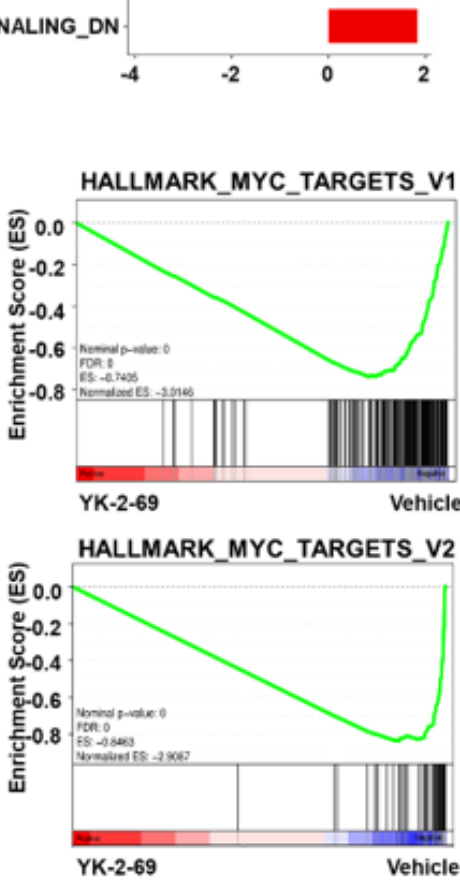

D
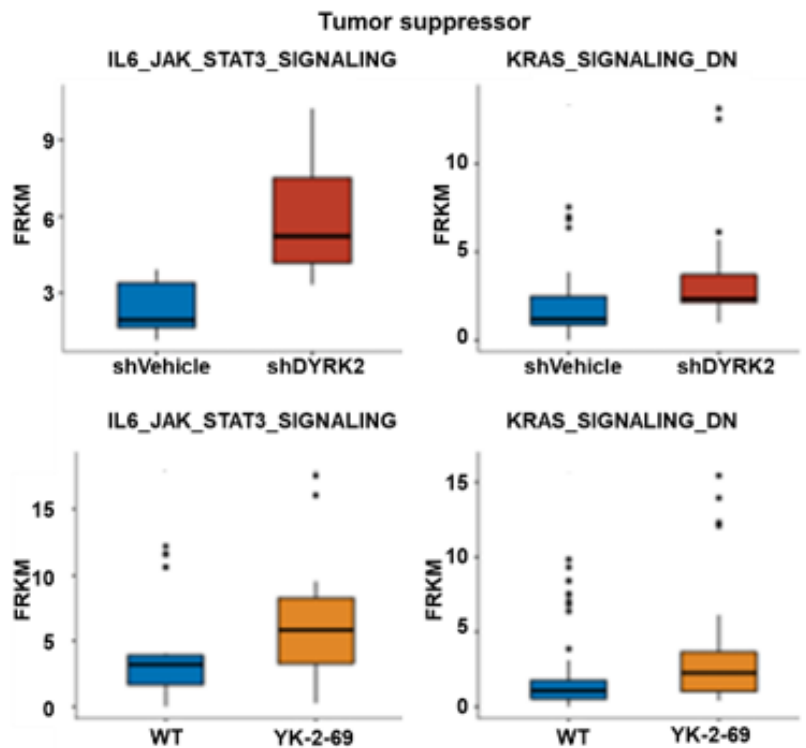

E

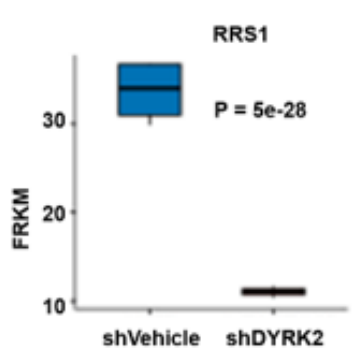

$\mathbf{F}$
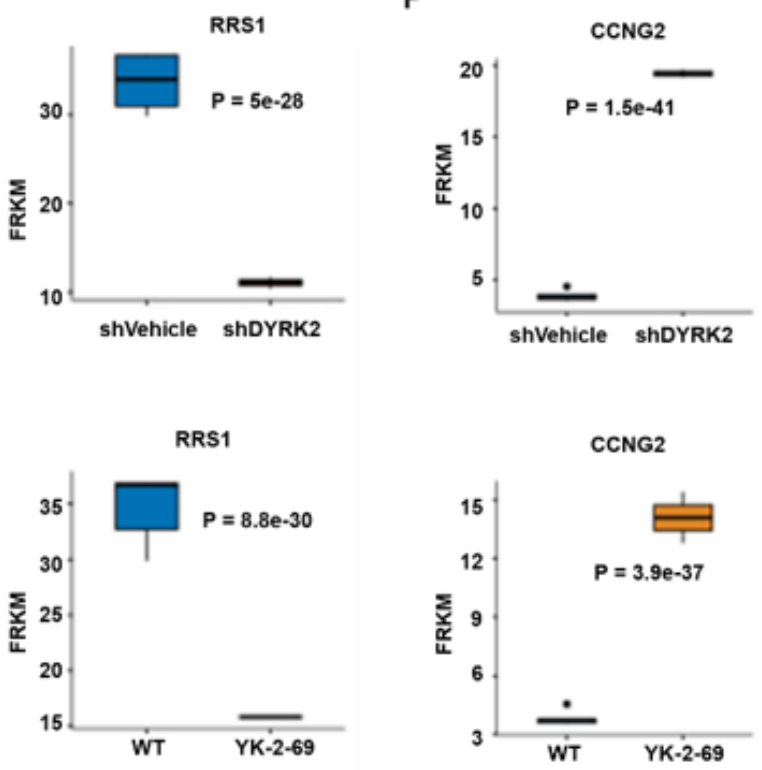

G

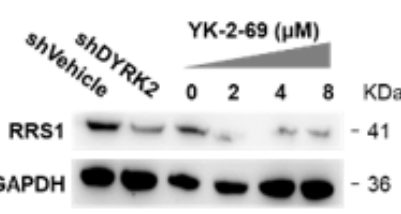

H

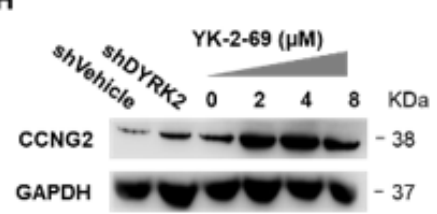

Figure 5

Transcriptome-wide RNA Sequencing Assays in PCa Cells. a, Venn diagram of the co-upregulated and codownregulated genes in DYRK2 KD- and YK-2-69-treated DU145 cells. b, Effects of YK-2-69 treatment and knock-down of DYRK2 on signal pathways. c, GSEA analysis of YK-2-69 treatment and knock-down of DYRK2 on MYC targets. d, Up-regulated hallmark gene sets by YK-2-69 treatment and knock-down of DYRK2 in DU-145 cell lines. e, Effects of YK-2-69 treatment and knock-down of DYRK2 on RRS1 in DU-145 
cell lines in transcriptome-wide RNA sequencing assays. $f$, Effects of $Y K-2-69$ treatment and knock-down of DYRK2 on CCNG2 in transcriptome-wide RNA sequencing assays. g, Effects of YK-2-69 treatment and knock-down of DYRK2 on RRS1 protein level in DU-145 cell lines. h, Effects of YK-2-69 treatment and knock-down of DYRK2 on CCNG2 protein level in DU-145 cell lines.

A

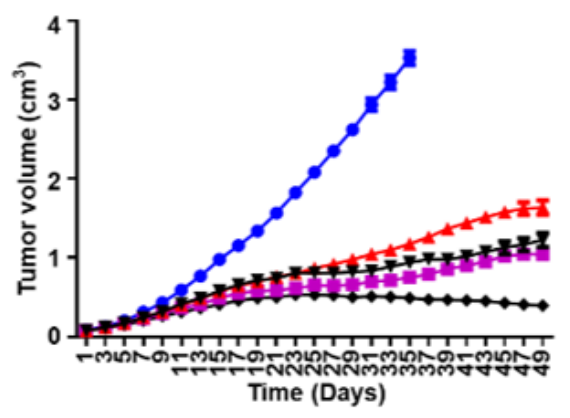

c

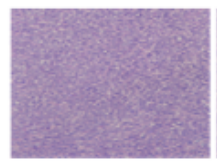

Vehicle

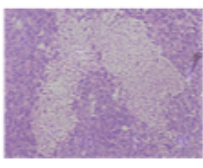

Low dose

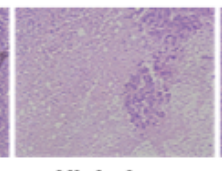

High dose

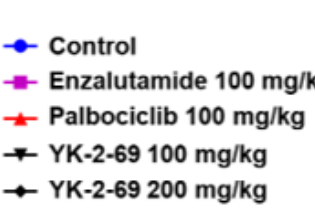

$\rightarrow$ YK-2-69 $200 \mathrm{mg} / \mathrm{kg}$
B

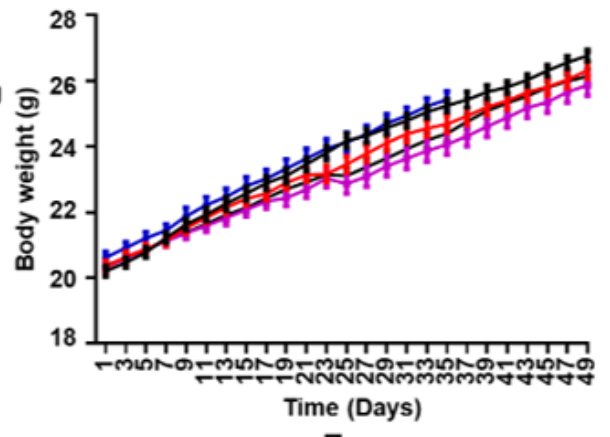

E

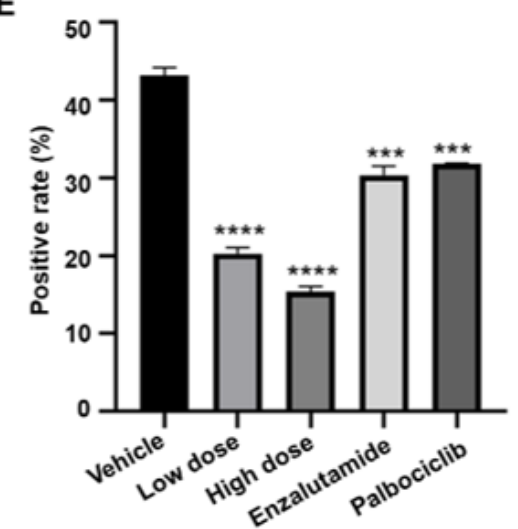

$\mathbf{F}$

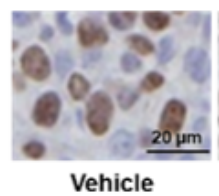

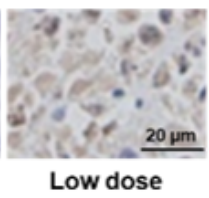

Low dose

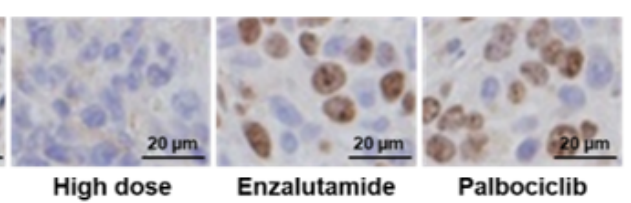

G

$\rightarrow$ Control

- Enzalutamide $100 \mathrm{mg} / \mathrm{kg}$

- Palbociclib $100 \mathrm{mg} / \mathrm{kg}$

$\rightarrow$ YK-2-69 $100 \mathrm{mg} / \mathrm{kg}$

$\longrightarrow \mathrm{YK}-2-69200 \mathrm{mg} / \mathrm{kg}$
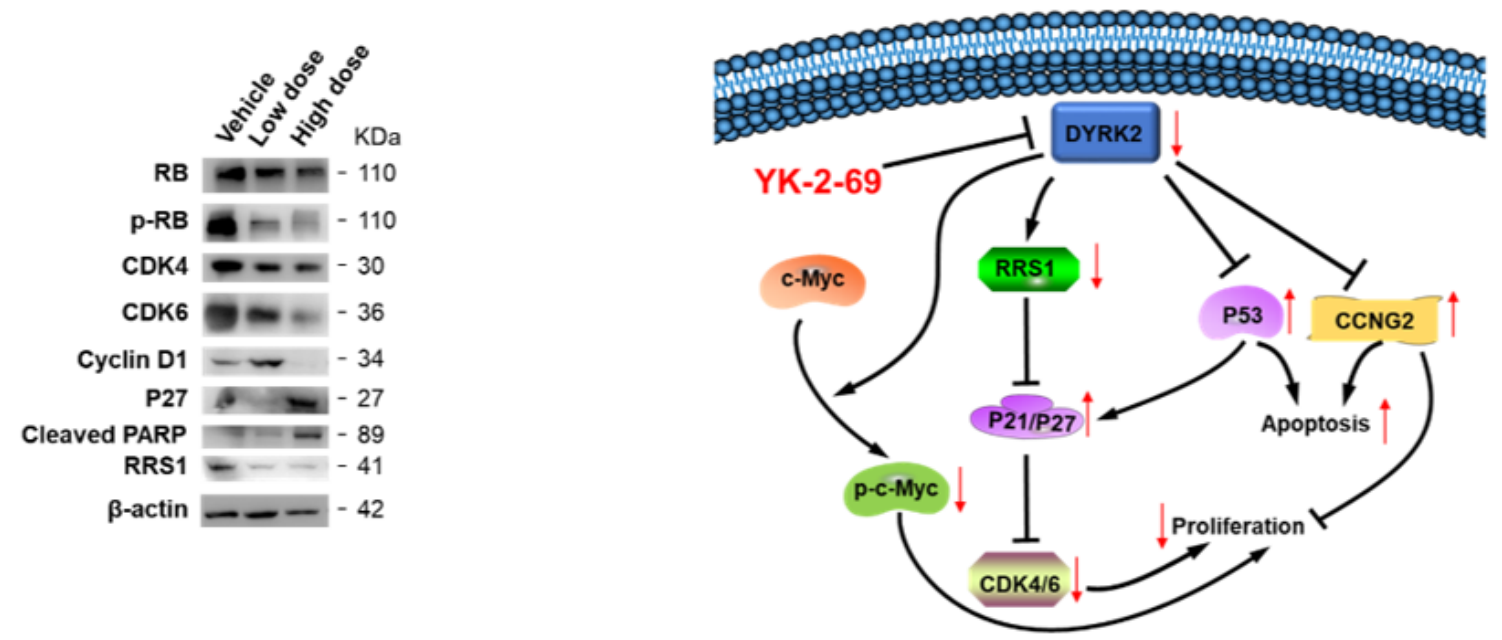

Figure 6

YK-2-69 Demonstrated Remarkable Antitumor Activities in Vivo. a, Tumor volume of nude mice. b, Body weight of nude mice. $c$, H\&E staining of tumor tissues. $d$, Representative images of immunohistochemical analysis of Ki-67 expression. e, Calculated Ki67 positive rate of each group $(n=3)$. $f$, Western blotting analysis of tumor lysate of DU-145 xenograft mice model of vehicle, enzalutamide, palbociclib and YK-269 treatment group. g, A proposed model for inhibition of DYRK2 by YK-2-69 for the treatment of PCa. *p $<0.05 ; * \star p<0.01 ; * * * p<0.001 ; * * * * p<0.0001$; unpaired Student's t-test. Error bars, mean $\pm S D, n=3$ 


\section{Supplementary Files}

This is a list of supplementary files associated with this preprint. Click to download.

- SupportingInformation.docx 